\title{
(The Struggle for) Refugee Integration into the Labour Market: Evidence from Europe
}

\author{
Francesco Fasani, Tommaso Frattini and Luigi Minale
}

December 2020

\begin{abstract}
We study the labour market performance of refugees vis-à-vis comparable migrants across twenty European countries and over time. In the first part of our analysis, we document that labour market outcomes for refugees are consistently worse than those for other migrants. Refugees are 11.6 percent less likely to have a job and 22 percent more likely to be unemployed than other migrants with similar characteristics. Moreover, their income, occupational quality and labour market participation are also relatively weaker. These gaps are larger relative to economic than noneconomic migrants, and persist until about 10-15 years after immigration. In the second part of our analysis, we investigate the role of economic conditions and migration and asylum policy regimes at the time of arrival in shaping integration paths of refugees. First, we find that immigrating in a recession produces scarring effects for all non-economic migrants but no differential effect for forced migrants, leaving little role for this channel to explain observed refugee gaps. Second, we focus on the impact on refugees of being subject to spatial dispersal policies. Our estimates imply that dispersed refugees experience a persistent impact on their residential choices and substantial long run losses in their economic integration with respect to non-dispersed refugees.
\end{abstract}

JEL codes: F22, J61, J15

Keywords: Refugee-migrant gap; assimilation; dispersal policies; initial conditions.

\footnotetext{
${ }^{\circ}$ Francesco Fasani: QMUL, CEPR, CReAM and IZA.

${ }^{\circ}$ Tommaso Frattini: University of Milan, LdA, CReAM, IZA and CEPR.

${ }^{\circ \circ}$ Luigi Minale: Universidad Carlos III de Madrid, CReAM and IZA.

We would like to thank Michael Amior, Jesus Fernandez-Huertas Moraga, Matti Sarvimaki, Jan Stuhler and participants at several seminars and conferences for their helpful comments, as well as Reinhard Weisser for his excellent research assistantship. We are very grateful to Nuffield Foundation for its financial support on this project (Grant OPD/42944). Luigi Minale also wishes to gratefully acknowledge financial support from the Ramon Areces Foundation, the Ministerio Economía y Competitividad (Spain), Maria de Maeztu grant (MDM 2014-0431), and the Comunidad de Madrid, MadEco-CM grant (S2015/HUM-3444).
} 


\section{Introduction}

Europe has recently experienced a major refugee crisis. The total number of individuals with recognized refugee status who reside in the EU15 area increased from approximately 1 million in 2014 to more than 2.5 million in 2018. In the same years, the total number of first time asylum applications received by EU-28 Member States countries reached an unprecedented figure of over 4.2 million. This dramatic increase in foreign-born citizens seeking protection sparked a heated debate in Western countries about refugees' impact on receiving societies and on adequate policies for dealing with this phenomenon. One crucial aspect of this debate is the extent to which Western countries can effectively integrate asylum seekers into their labour markets and societies (Fernández-Huertas Moraga and Rapoport 2015; Dustmann et al. 2017; Hatton 2017).

Despite its policy relevance, the integration of refugees into host countries' labour markets is still an understudied area relative to the large body of evidence on the assimilation of economic migrants (see Borjas 1999 and Kerr and Kerr 2011 for reviews of this latter evidence). In this paper, we provide a comprehensive analysis of the socio-economic integration of refugee migrants in European countries and analyse the role of economic and policy conditions at the time of arrival in explaining their integration paths. We do so by employing repeated cross-sectional micro data from the European Labour Force Survey - which enable us to identify individuals who migrated for humanitarian reasons - and by studying the labour market performance of refugees vis-à-vis comparable migrants across several European countries and over time.

In the first part of the paper, we estimate refugee-migrant gaps for a comprehensive set of outcomes. In our estimates, we condition on observable personal characteristics as well as on unobservable factors (captured by a rich set of fixed effects) common to individuals migrating from the same area, belonging to the same arrival cohort and arriving to the same destination country. We find that refugees' outcomes are consistently worse than those of comparable migrants. Not only does this labour market gap not seem motivated by the different observable individual characteristics, but 60-80 percent of the "refugee gap" conditional on age, gender and education remains unexplained even when we control for unobservables using origin area, entry cohort and destination country fixed effects, and the interactions between them. In our preferred estimates, refugees' employment and unemployment probabilities are 7.8 percentage points (11.6 percent) below and 3.1 percentage points ( 22 percent) above, respectively, those of non-refugee 
migrants. These refugee-immigrant gaps are larger relative to economic than non-economic migrants, they are smaller for women than for men, vary across areas of origin and tend to persist up to 10-15 years after arrival in the host country. Our results also suggest that the worse health status and lower language proficiency of refugees may partly explain their weaker labour market performance, and that refugees perceive more hurdles than other migrants in finding jobs that suit their qualifications.

In the second part of the paper, we investigate the role of initial economic and asylum policy conditions in shaping integration paths of refugees versus migrants. We first study the effects of immigrating into a recession. Being forced to flee violence and conflict, refugees are likely to be less responsive to the state of the host country's economy than economic migrants, potentially increasing their likelihood of arriving in destination countries during economic downturns. In addition, initial scarring effects may be more profound and/or persistent for refugees relative to other migrants. After matching individuals in our sample with economic conditions at the time of their arrival in host countries, we test whether immigrating in a recession produces lasting negative effects on immigrants' economic integration and whether the effect is stronger for refugees. We find evidence of scarring effects of economic downturns for all immigrants, while we observe a differential effect for forced migrants only when we compare them to economic migrants. Accounting for the role of recessions at entry does not seem to significantly reduce the estimated refugee-immigrant gap, leaving little role for this channel to explain observed differences in integration profiles. We then turn our empirical analysis to the impact of migration and asylum policies at the time of arrival on future economic integration of refugees, relative to comparable migrants. Since refugees and other migrants are exposed to distinct policy regimes, at least in the initial period of their host country residence, these initial differences can shape their respective future integration trajectories and influence the gap we observe. We first use broad indicators of policy strictness regarding both entry and residence rules for economic, family and refugee migrants. Our findings are in line with restrictive policies on non-refugee migrants reducing the observed gap with refugees, although estimates are fairly imprecise. We then focus on a specific component of asylum policy, namely Dispersal Policies of asylum seekers and refugees (DPs), a relatively common scheme in European countries, whereby immigrants seeking humanitarian protection are centrally allocated to specific areas of the country. DPs typically pursue the aim of preventing ethnic enclave formation by scattering refugees across the country and often away from 
larger cities. These policies may improve refugees' outcomes if ethnical segregation is damaging for their economic integration. However, constraining the geographical mobility of refugee migrants and making centralized allocation decisions that are often orthogonal to local labour demand may produce negative effects on refugees' labour market performance. We estimate the consequences of DPs for the refugee-migrant gaps by exploiting the differential timing of DPs enactment across European countries which provides us with variation across both entry cohorts within the same country and within entry cohorts in Europe across countries. We find clear evidence of a persistent detrimental impact of DPs on dispersed refugees. For instance, the refugee-migrant gap in employment is 4.5 p.p. larger for refugees who arrived when a DP was in place than for those who were not exposed to such a policy. One mechanism through which the detrimental effect of DPs seems to operate is by permanently altering the geographical distribution of refugees in host countries. Indeed, in the last part of our analysis, we document that dispersed refugees are more likely to reside in areas characterized by systematically less favourable conditions for labour market integration than non-dispersed refugees.

Our paper contributes primarily to the literature on the labour market integration of refugee migrants. Until recently, this area of research has received far less attention than that of economic migrants for various reasons, among them the scarcity of data allowing explicit differentiation of immigrants by entry category. ${ }^{1}$ Nevertheless, evidence from both North America (Cortes 2004; Bevelander and Pendakur 2014) and selected European countries (Bratsberg et al. 2014; Ruiz and Vargas-Silva 2018; Sarvimäki 2017) hints at a large initial labour market disadvantage of refugees, albeit one that tends to shrink over time (see Bevelander 2016, Becker and Ferrara 2019, and Brell et al. 2020 for recent reviews of this literature). Our paper adds to this literature by developing the first comparable and systematic analysis of the socio-economic integration of refugee migrants across many European countries and over time. In addition, by focusing our analysis on labour market gaps between refugees and other migrants with similar characteristics, we provide estimates that are, at the same time, compelling and directly relevant for policy-making. A second area we contribute to is the literature on the role of economic and policy conditions at arrival in shaping future integration paths of immigrants. It has long been known that labour market

\footnotetext{
${ }^{1}$ Some studies rely on information on country of origin and entry cohort to identify immigrants likely to be refugees (e.g. Edin et al., 2003 and Cortes, 2004). Even the administrative record data to which researchers have recently begun gaining access is currently limited to only a few host countries: see Bratsberg et al. (2014) for Norway, Luik et al. (2016) for Sweden and Hainmueller et al. (2016) for Switzerland.
} 
conditions at the time of labour market entry may have persistent effects on workers' careers (see e.g. Kahn, 2010; Oreopoulos et al., 2012; Altonji et al. 2016). Likewise, for migrant workers entering the country during a recession or an expansion can impact future integration trajectories. The literature in this case is more limited: following the initial evidence from Chiswick and Miller (2002), a few studies have tried to deal with migrant selection into positive stages of business cycle by exploiting features of either the asylum (Aslund and Rooth, 2007; Mask, forthcoming) or the family reunification policies at destination (Barsbai, Steinmayr and Winter, 2020). Thirdly, our paper brings novel evidence to the literature on dispersal policies of asylum seekers and refugees. Some studies have relied on the quasi-random allocation imposed by these policies to generate exogenous variation in initial conditions faced by refugees in regional density of co-ethnic networks (Edin et al. 2003; Damm 2009 and 2014; Beaman 2012; Battisti et al. 2016; Martén et al. 2019; Dagnelie et al. 2019) or local labour market demand (Åslund and Rooth 2007; Godøy 2017; Azlor et al. 2020). Other papers have exploited these allocation policies to identify causal impacts on different outcomes, such as crime (Bell et al. 2013; Damm and Dustmann 2014; Couttenier et al. 2019), employment and wages of native workers (Foged and Peri, 2016) or politics (Dustmann et al. 2019; Bratsberg et al. forthcoming). However, direct evidence on the overall labour market impact of being subject to a dispersal policy is extremely scarce. The only exception is the evaluation of the Swedish Settlement Policy by Edin et al. (2004), which shows that dispersed refugees are less likely to be employed, have lower earnings, and rely more on welfare than non-dispersed refugees. Our paper complements and expands on this evidence for Sweden by providing the first assessment of the medium and long-term effects of dispersal on refugees arrived over the last three decades across European countries. Our findings suggest that dispersed refugees experience a persistent impact on their residential choices and substantial long-run losses in their economic integration. These results speak directly to recent work on refugee matching that has discussed ways to improve the allocation of refugees both across countries (Fernández-Huertas Moraga and Rapoport, 2014 and 2015; Jones and Teytelboym, 2017) and across locations within any given country (Bansak et al., 2018; Trapp et al., 2018). In particular, these latter studies show that improving current allocation practices of hosting governments would produce large employment gain for refugees, a result supported by our findings.

The paper unfolds as follows. Section 2 introduces our data and provides descriptive evidence on the labour market outcomes of different migrant groups relative to natives. Section 3 reports the 
results of our main empirical analysis of refugees versus other migrants. Section 4 presents the results on the role of conditions at arrival in explaining refugee-migrant gaps. Section 5 concludes with a brief discussion of policy implications.

\section{Data and Descriptive Evidence}

\subsection{The European Labour Force Survey}

Our analysis is based on data from the European Labour Force Survey (EULFS), a large household survey of people aged 15 and over covering the 28 member states of the European Union, the candidate countries (the Former Yugoslav Republic of Macedonia and Turkey) and three countries of the European Free Trade Association (Iceland, Norway and Switzerland). Specifically, we use two ad hoc modules on migrant labour market outcomes collected in 2008 and 2014, which contain additional questions on migrant experience in the host country. The EULFS reports information on individual circumstances, including country of birth, demographic characteristics and years since migration, as well as immigrant labour market status and type of occupation. The 2014 module also includes information on an individual's position in the host country national income distribution. ${ }^{2}$ Of particular relevance for our study is the fact that the questionnaires for the ad hoc modules include information about the main reason for migration, thereby allowing us to distinguish refugees from other migrants. This reason-for-migration question was asked of all nonnative individuals who arrived in the country of residence when they were 15 years of age or older, with interviewees given the choice of employment, study, international protection or family reunification as the primary motivation. ${ }^{3}$ Throughout the paper, we designate all respondents who selected 'international protection' as refugees and all those choosing another reason as (other) migrants. $^{4}$

\footnotetext{
${ }^{2}$ The ad hoc modules are available for both 2008 and 2014 for the following 13 countries: Austria, Belgium, Cyprus, France, Greece, Italy, Lithuania, Luxembourg, Norway, Portugal, Spain, Sweden, and the UK. Data for Germany, Ireland and the Netherlands are available only for 2008 and those for Bulgaria, Croatia, the Czech Republic, Estonia, Finland, Hungary, Latvia, Malta, Poland, Romania, Slovakia, Slovenia and Switzerland only for 2014. Income data are unavailable for the Czech Republic, France, Hungary, Norway and Sweden, and the EULFS does not report wages. 3 Specifically, in 2008, respondents were asked to choose among eight alternative reasons for migration: (1) employment, intra-corporate transfer; (2) employment, job found before migrating; (3) employment, no job found before migrating; (4) study; (5) international protection; (6) accompanying family/family reunification; (7) family formation, and (8) other. In 2014, the categories were reduced to six.

${ }^{4}$ In our sample, we define as non-natives (refugees and other immigrants) all individuals who are "foreign born", except for Germany where non-natives are defined as "foreign nationals". When information about the country of birth is missing, we use the parents' country of origin to determine the individual's non-native status.
} 


\subsection{Preliminary Evidence: Natives, Migrants and Refugees}

We set the background for our main analysis on the labour market gap between refugees and migrants by first comparing both groups with natives in European countries. In order to do so, we add observations on native workers (approximately 900 thousand observations) from the EULFS to our main sample, and estimate linear probability models for each of the following six labour market outcomes: employment status, unemployment, labour force participation, high skilled occupation and being in the lowest or highest decile of the income distribution. ${ }^{5}$ We include dummies that identify EU immigrants, non-EU immigrants and refugees, whereas natives are the excluded category. We obtain baseline gaps by exclusively conditioning on host country-year interaction dummies - to capture national business cycle fluctuations common to all four groups of workers - while conditional gaps are estimated after including dummies for gender, 5-year age groups and three educational levels. Figure 1 outlines the baseline and conditional percentage point differences in labour market outcomes between natives and each of the three immigrant groups. The figure clearly shows that, across Europe, immigrants tend to have worse labour market performance than natives regardless of their origin and reason for migration, whereas the gap tends to be small for EU migrants, generally wider for non-EU immigrants and even larger for refugees. As regards baseline employment probability gaps (Figure 1A), EU migrants are 1.4 percentage points less likely than natives to be employed (about minus 2 percent relative to the native average employment rate, which is at 71 percent in our sample), whereas the gap increases to 6.9 percentage points (10 percent) for non-EU migrants and to 17.1 percentage points ( 24 percent) for refugees. When we condition out intergroup differences in age, gender and education, the gaps with natives tend to increase because immigrants are on average younger and better educated. A similar pattern is evident for unemployment (Figure 1B), and for labour force participation (Figure 1C). Even focusing on employed individuals, non-natives tend to do worse than natives in terms of both occupational skill content and income. Both migrants and refugees are less frequently employed in high-skilled occupations (Figure 1D) and considerably more (less) likely than natives

\footnotetext{
${ }^{5}$ We define these indicators for all individuals in the 25-64 age bracket as follows: employment rate $=$ the share of individuals from the working age population who are either in employment or self-employed; labour force participation rate $=$ the share of individuals who are in the labour force (i.e. either employed or job hunting); unemployment rate $=$ the share of individuals from the total labour force who are job hunting; skilled occupation $=$ belonging to one of the three major ISCO-08 groups: Group 1: managers; Group 2: professionals; Group 3: technicians and associate professionals.
} 
to be in the bottom (top) decile of the national income distribution (Figure 1E(F)). Appendix Figure A 1 graphs the evolution of the gaps in employment (panel A) and unemployment (panel B) probabilities for the three immigrant groups with respect to natives, by years since arrival in the host country. Recently arrived refugees have extremely large gaps in both employment and unemployment probability, not only with respect to natives but also to other immigrants: although gaps in labour market outcomes decrease with time spent in the host country for all immigrants, they remain sizeable even after 15 years or more for refugees and non-EU migrants.

Figure 1-Immigrant-Native Probability Gaps in Labour Market Outcomes, by Migration Status
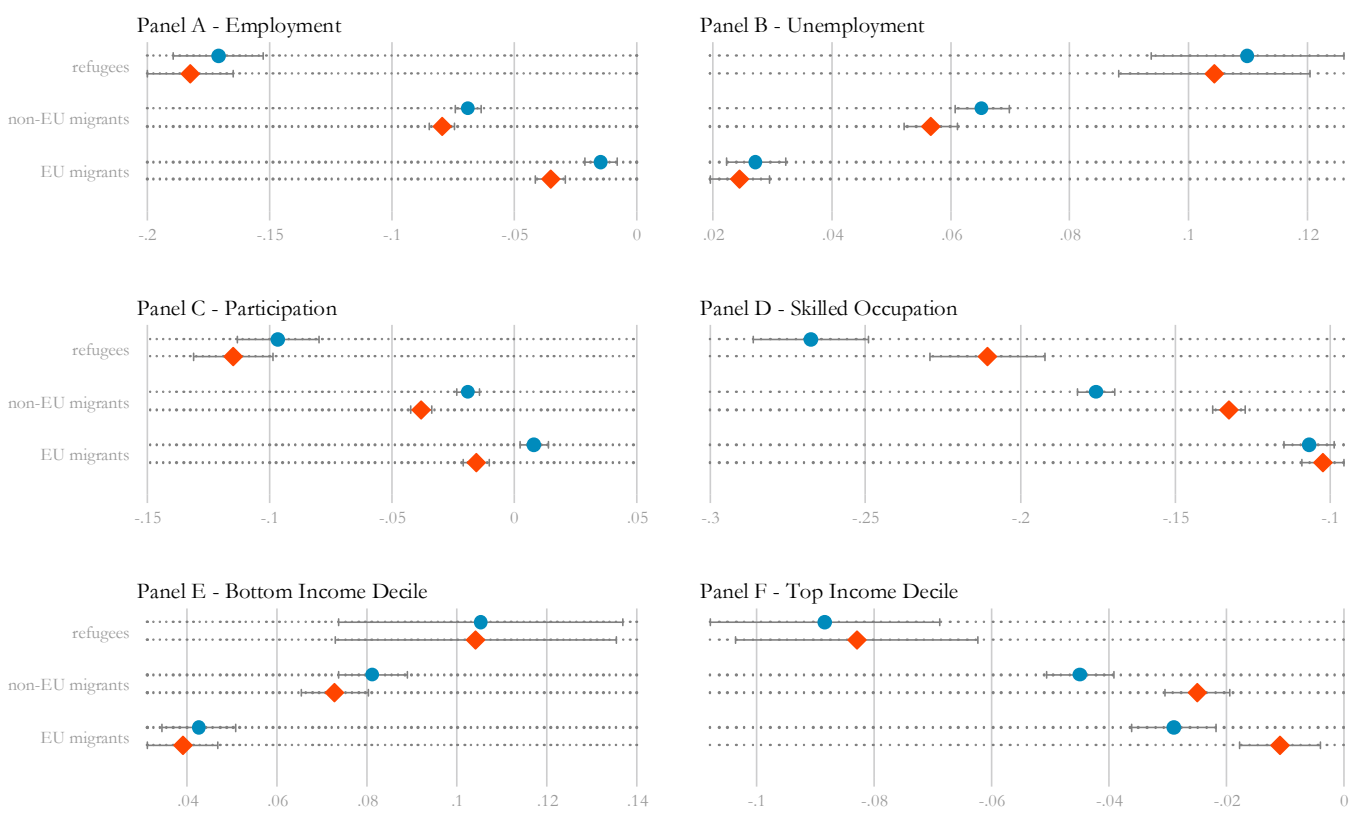

- baseline

Notes. The figure reports baseline and conditional differences (and 90 percent confidence intervals based on robust standard errors) for various labour market outcomes between EU and non-EU migrants and natives, as well as between refugees and natives. The dependent variable is, alternatively, a dummy for whether the individual is employed (A); job hunting versus being in employment (B); employed or job hunting versus being out of the labour force (C); employed in a high skilled occupation versus being employed in other occupations (D); in the bottom decile of the national income distribution $(\mathrm{E})$; or in the top decile of the national income distribution $(\mathrm{F})$. Baseline estimates are obtained from linear probability regressions that include destination country-observation year interaction dummies. Conditional gaps further control for gender, age and education. The sample comprises individuals aged 25-64, who are not in full-time education or military service; full sample size: 982,970 observation. 


\subsection{Descriptive Statistics}

In the core of our paper, we focus our analysis on comparing outcomes of refugees with those of migrants with similar characteristics who have not sought humanitarian protection. We thus exclude from the sample natives and migrants from EU-15 countries and from North America and Oceania, while keeping all refugees and other non-EU-15 migrants. Our estimation sample include 67,284 foreign born individuals, 5,223 (7.8 percent) of them refugees, who are in working age (25-64), are not in full-time education or military service and have valid information on immigrant status, reason for migration, gender, education, age or origin area. ${ }^{6}$

Descriptive statistics for this sample are presented in Table 1. The share of males is larger among refugees than other migrants and the former are relatively older. As far as educational qualifications are concerned, refugees and other migrants display fairly similar distributions with about one fourth of individuals in both groups having tertiary education. Refugees have higher migration seniority than other migrants: 44 percent of refugees, for instance, have been in the host country since before 1995, versus 31 percent among the other migrants. As regards area of origin, the table shows 7 percent of refugees originating from one of the EU new member states, and 31 percent from other non-EU European countries. An additional 25 percent are from North Africa and the Middle East, with the remainder almost equally split between sub-Saharan Africa (18 percent) and South and East Asia (17 percent). Only 3 percent of the refugees in the sample originate from Latin American countries. Table 1 also reports descriptive statistics for the labour market indicators on which we focus throughout the empirical analysis: employment rate, labour force participation rate, unemployment rate, being employed in a skilled occupation, and being in the top or bottom decile of the host country income distribution. For these variables, refugees are on average at a disadvantage relative to comparable non-refugee migrants. For instance, the employment rate among refugees is 60 percent, their participation rate is 71 percent and their unemployment rate is 16 percent, with corresponding values for other migrants of 67, 78 and 14 percent, respectively. The share of employed workers in a skilled occupation is similar between refugees and other migrants, 22 and 23 percent respectively. Finally, the share of refugees in the

\footnotetext{
${ }^{6}$ We exclude all observations from countries-survey years for which the number of refugees sampled is less than 30 individuals (i.e. Bulgaria, Czech Republic, Estonia, Latvia, Lithuania, Malta, Poland, Romania, and Slovakia). See Appendix Table A 1 for the sample size for each migrant group by host country.
} 
top income decile is only 3 percent, almost half of the corresponding value for other migrants ( 5 percent).

Table 1 - Summary Statistics

\begin{tabular}{|c|c|c|}
\hline & Refugees & Other Migrants \\
\hline Men & 0.60 & 0.47 \\
\hline \multicolumn{3}{|l|}{ Age group: } \\
\hline $25 / 39$ & 0.33 & 0.50 \\
\hline $40 / 54$ & 0.50 & 0.37 \\
\hline $55 / 64$ & 0.17 & 0.13 \\
\hline \multicolumn{3}{|l|}{ Education: } \\
\hline Tertiary & 0.24 & 0.24 \\
\hline Upper secondary & 0.38 & 0.37 \\
\hline Lower secondary & 0.38 & 0.38 \\
\hline \multicolumn{3}{|l|}{ Broad entry cohort: } \\
\hline Before 1995 & 0.44 & 0.31 \\
\hline 1995-2003 & 0.41 & 0.42 \\
\hline 2004-2007 & 0.09 & 0.20 \\
\hline $2008-2013$ & 0.06 & 0.08 \\
\hline \multicolumn{3}{|l|}{ Area of origin: } \\
\hline NSM12 / NMS13 & 0.07 & 0.19 \\
\hline Other Europe & 0.31 & 0.18 \\
\hline North Africa and Middle East & 0.25 & 0.19 \\
\hline Other Africa & 0.18 & 0.10 \\
\hline South-East Asia & 0.17 & 0.14 \\
\hline Latin America & 0.03 & 0.21 \\
\hline \multicolumn{3}{|l|}{ Labour market outcomes: } \\
\hline Employment rate & 0.60 & 0.67 \\
\hline Participation rate & 0.71 & 0.78 \\
\hline Unemployment rate & 0.16 & 0.14 \\
\hline Skilled occupation & 0.22 & 0.23 \\
\hline Top income decile & 0.03 & 0.05 \\
\hline Bottom income decile & 0.17 & 0.16 \\
\hline Observations & 5,223 & 62,061 \\
\hline
\end{tabular}

Notes. The table reports summary statistics for our estimating sample, separately for refugees and other immigrants from non-EU15 countries (aged 25-64). The variable reported are: share of men; distribution by age group, education, broad entry cohorts and area of origin; employment, participation and unemployment rate; share of individuals employed in a skilled occupation (out of all employed individuals), in the top and in the bottom deciles of the national income distribution. 


\section{The Gap between Refugees and Migrants}

\subsection{Estimating Equation}

To formally explore the size of the refugee-migrant gap in labour market performances and the role of observable as well as of host country- or cohort- specific unobservable characteristics in explaining it, we estimate the following linear probability model:

$$
y_{i s d T t}=\beta r e f_{i s d T t}+\gamma X_{i s d T t}+\mu_{d t}+\varphi_{T}+\omega_{s}+\varepsilon_{i s d T t}
$$

where $y_{i s d T t}$ is a (binary) labour market outcome for individual $i$ from origin area $s$ who arrived in her current country of residence $d$ in year $T$ and was interviewed in survey year $t$ (2008 or 2014); ${ }^{7} r e f_{\text {isdTt }}$ is an indicator variable that takes value one for refugees (i.e. migrants arrived for humanitarian protection) and zero for all other migrants; $X_{i s d T t}$ is a vector of individual controls (age, gender, education); $\mu_{d t}$ is a set of destination country-interview year fixed effects capturing any economic or non-economic conditions in the destination country at the time of interview; $\varphi_{T}$ is a set of arrival cohort fixed effects that captures all unobservable factors common to individuals arriving in Europe in the same year, ${ }^{8} \omega_{s}$ is a set of origin area fixed effects capturing common time invariant characteristics of migrants arriving from the same geographic area; ${ }^{9}$ and $\varepsilon_{s d T t}$ is an idiosyncratic shock. Unless otherwise specified, we use heteroscedasticity robust standard errors to account for the fact that our dependent variables are binary. In order to better control for unobservable characteristics and shocks that might have determined the labour market outcomes of individuals entering the same destination country in the same year or leaving the same area in the same year we can then incorporate two-way fixed effects into our specification. In particular, we condition on host country-entry cohort and on area of origin-entry cohort fixed effects. The former set of dummies captures all initial conditions (e.g. unemployment, GDP growth, migrant

\footnotetext{
${ }^{7}$ Note that although the country of residence at the time of the survey does not necessarily correspond to the country in which individuals originally migrated to when they first moved to Europe, intra-EU mobility of non-EU citizens is extremely limited since residence permits are only valid within the EU country that issued them. Analysis of the 2014 EULFS data indicates that only $5 \%$ of non-EU migrants in our sample (who have moved to the current country of residence less than ten years before the interview) report having lived in another EU28 country in the previous ten years, suggesting that for the vast majority of migrants in our sample the country of current residence coincides with that of first arrival in Europe.

${ }^{8}$ The specific year of arrival is available for individuals arrived 10 or less years before the interview. For the others, earlier arrivals, entry cohorts fixed effects refer to five-year groups (e.g. 1980-84, 1985-89).

${ }^{9}$ We include dummies for seven origin areas: EU new member states; other European countries; North Africa and the Middle East; other African countries; South and East Asia; North America and Oceania; and Latin America.
} 
stock) in the destination country to which all migrants belonging to the same arrival cohort, irrespective of refugee status, were exposed, while the latter set controls for any common shock affecting migrants arriving in Europe from the same origin area in the same cohort.

The fact that refugees may face a more difficult integration than other groups of migrants, especially upon arrival, is not unexpected. Refugees were exposed to violence, conflict and persecution, with potentially lasting effects on their health and mental health that may hinder their socio-economic integration. Further, having been forced to suddenly leave their home countries, with limited control on the timing and the final destination of their move, refugees are more likely to experience a worse match in host countries - in terms of their skills, aspirations and availability of ethnic networks - than the average migrant. Whether refugees are able to bridge their initial disadvantage, however, is an empirical question. The direct comparison of one type of migrant with another eliminates most of the major measurement problems common in studies comparing migrants with natives having similar education and host country work experience. In addition, this comparison allows us to reasonably rule out certain potential explanations of the observed gap such as discrimination in the labour market, cultural and language barriers and obstacles to the recognition of foreign qualifications - that are likely to affect similar migrants in similar ways, irrespective of their initial reason for migration. Finally, by conditioning on a rich set of fixed effects that capture the unobservable characteristics, shocks, determinants and other factors common to, for example, all individuals emigrating from a certain area in the same year or all individuals arriving in a specific host country at the same time, we can assess the extent to which absorbing this unobserved heterogeneity reduces the observed gap.

\subsection{Baseline Results}

In Table 2, we report the coefficients estimated from the linear probability model in equation (1) for the likelihood of employment, incorporating the different controls and fixed effects stepwise. We report estimates for the full sample in Panel A. Across all specifications, we consistently find a large and significant negative employment gap between refugees and comparable migrants. When conditioning exclusively on host country-survey year dummies, the employment differential is minus 6.1 percentage point (column 1). This baseline initially increases when controlling for gender and age (column 2) but then decreases with the incorporation of education dummies (column 3). As a result, the gap conditional on individual characteristics is minus 8.6 
percentage points (column 3), suggesting that refugees are overall relatively better selected from the distribution of employment-correlated observable characteristics than other migrants. When we condition on area of origin (column 4), this gap shrinks substantially by almost 20 percent (minus 7.2 percentage points), suggesting that refugees disproportionately originate from areas associated with weaker EU labour market performance. Conversely, when we control for entry cohort (column 5), the gap increases slightly, implying that refugees are slightly overrepresented in earlier cohorts, which had more time to integrate. ${ }^{10}$ Finally, we include the two-way fixed effects for host country-entry cohort and for area of origin-entry cohort that we discussed in the previous section. These last estimates (column 6) show that allowing entry cohort effects to vary by host country and by source area generates no further reduction in the employment gap between migrants and refugees. Thus, in our most restrictive specification the refugee-migrant employment rate differential is 7.8 percentage points, suggesting that refugees are about 11.6 percent less likely to be employed than comparable migrants (whose unconditional employment probability is 0.67 ).

The group of non-refugee migrants is highly heterogeneous and includes individuals who migrated for different reasons (e.g. employment, family reunification, study) and were granted different types of visas upon arrival in host countries. To explore how refugees' performance compares to those of different sub-groups of migrants, in the lower part of Table 2 we separately estimate refugee-migrants gaps in employment with respect to economic (panel B) and non-economic migrants (panel C). ${ }^{11}$ As expected from the differences in the selection process between these two groups of migrants, they display a fairly distinct labour market integration, with employment rate being at $77 \%$ for economic migrants and at $59 \%$ for non-economic migrants (as reported in Table 2). The employment gap of refugees relative to economic migrants is large, reaching almost (minus) 17 percentage points in our most restrictive specification (column 6), or 22 percent of the mean outcome for this group of migrants (Panel B). The gap shrinks to about 5 percentage points relative to non-economic migrants, but it is still strongly significant and sizeable, corresponding to about 8 percent of the mean employment of this migrant group (column 6, Panel C).

\footnotetext{
${ }^{10}$ Note that our findings about how much each group of covariates contributes to shrinking rather than widening the refugee gap may depend on the specific sequential inclusion of controls that we followed. In order to check for that, we perform a Gelbach decomposition (Gelbach 2016) for the estimates of the employment refugee gap. Appendix Table A 2 reports such decomposition that confirms findings in Table 2.

${ }^{11}$ We classify as economic migrants those who answer "employment" to the question about the reason for migration, and as non-economic migrants those who reported "family formation/reunification", "study", or "other" as reason for migration.
} 
Table 2 - Refugee-Immigrant Gap: Employment Probability

\begin{tabular}{|c|c|c|c|c|c|c|}
\hline & (1) & (2) & (3) & $(4)$ & (5) & (6) \\
\hline \multirow[b]{2}{*}{ Refugee } & \multicolumn{6}{|c|}{ Panel A - Refugees vs Migrants (Any) } \\
\hline & $\begin{array}{c}-0.061 * * * \\
(0.012)\end{array}$ & $\begin{array}{c}-0.091^{* * *} \\
(0.012)\end{array}$ & $\begin{array}{c}-0.086^{* * *} \\
(0.012)\end{array}$ & $\begin{array}{c}-0.072 * * * \\
(0.011)\end{array}$ & $\begin{array}{c}-0.076^{* * *} \\
(0.011)\end{array}$ & $\begin{array}{c}-0.078^{* * *} \\
(0.011)\end{array}$ \\
\hline Observations & \multicolumn{6}{|c|}{67,284} \\
\hline Mean Outcome - Migrants & \multicolumn{6}{|c|}{0.67} \\
\hline & \multicolumn{6}{|c|}{ Panel B - Refugees vs Economic Migrants } \\
\hline Refugee & $\begin{array}{c}-0.168 * * * \\
(0.014)\end{array}$ & $\begin{array}{c}-0.172 * * * \\
(0.013)\end{array}$ & $\begin{array}{c}-0.168^{* * *} \\
(0.013)\end{array}$ & $\begin{array}{c}-0.152^{* * *} \\
(0.013)\end{array}$ & $\begin{array}{c}-0.170^{* * *} \\
(0.014)\end{array}$ & $\begin{array}{c}-0.168^{* * *} \\
(0.014)\end{array}$ \\
\hline Observations & \multicolumn{6}{|c|}{32,376} \\
\hline Mean Outcome - Migrants & \multicolumn{6}{|c|}{0.77} \\
\hline & \multicolumn{6}{|c|}{ Panel C - Refugees vs Non-Economic Migrants } \\
\hline Refugee & $\begin{array}{l}-0.014 \\
(0.012)\end{array}$ & $\begin{array}{c}-0.071^{* * *} \\
(0.012)\end{array}$ & $\begin{array}{c}-0.061^{* * *} \\
(0.012)\end{array}$ & $\begin{array}{c}-0.052^{* * *} \\
(0.012)\end{array}$ & $\begin{array}{c}-0.044^{* * *} \\
(0.012)\end{array}$ & $\begin{array}{c}-0.049 * * * \\
(0.012)\end{array}$ \\
\hline Observations & \multicolumn{6}{|c|}{40,131} \\
\hline Mean Outcome - Migrants & \multicolumn{6}{|c|}{0.59} \\
\hline Host country*Year & YES & YES & YES & YES & YES & YES \\
\hline Gender and Age & & YES & YES & YES & YES & YES \\
\hline Education & & & YES & YES & YES & YES \\
\hline Source Area FE & & & & YES & YES & \\
\hline Entry Cohort FE & & & & & YES & \\
\hline Entry Cohort ${ }^{*}$ Host Country FE & & & & & & YES \\
\hline Entry Cohort*Source Area FE & & & & & & YES \\
\hline
\end{tabular}

Notes. The table reports the coefficients for a refugee migrant dummy, estimated by linear regression with an employment dummy as the dependent variable. In Panel A the sample comprises refugees and non-EU15 immigrants (aged 25-64). In Panel B the sample is restricted to refugees and non-EU15 economic migrants, while in Panel C it is restricted to refugees and non-EU15 non-economic migrants (i.e. those entered for family reunification/formation, study or other reasons). All specifications include destination country-observation year interaction dummies. "Gender, Age, Education" are dummy variables for gender, five-year age groups and at most upper secondary or tertiary education (with at most lower secondary education as the excluded category). "Source Area FE" are dummy variables covering the seven major source regions (13 EU new member states; other European countries; North Africa and Middle East; other African countries; South and East Asia; North America and Oceania; Latin America). "Entry cohort FE" are dummy variables for year (or groups of years) of arrival in the host country. "Host country FE" are dummies for the twenty destination countries in the sample. Robust standard errors in parentheses. $* * * \mathrm{p}<0.01, * * \mathrm{p}<0.05, * \mathrm{p}<0.1$.

In Table 3, we consider additional labour market outcomes - participation (column 1), unemployment (column 2), employment in a skilled occupation (column 3 ) and being in the bottom or in the top decile of the income distribution (columns 4-5) - and report estimates of the refugee gap from our most complete specification. As in Table 2, we report estimates for the full sample of migrants (Panel A) and then separately for economic (Panel B) and non-economic migrants (Panel C). Estimates in Panel A reveal that the likelihood of refugee labour market participation is relatively low, about 6.3 percentage points ( 8 percent) less than for comparable non-refugee immigrants (column 1). The unemployment probability is 3.1 percentage points (22 percent) higher for refugees than for other migrants (column 2). Even among those who are employed, 
refugees are disadvantaged relative to other immigrants. Not only are they 7 percentage points (30 percent) less likely to be in a high-skilled occupation than other migrants with similar characteristics (column 3), but also they display substantially higher probability to be in the bottom decile and lower probability to be in the top decile of each host country's income distribution than other immigrants. As shown for employment in Table 2, gaps tend to be larger when comparing refugees with economic than non-economic migrants (Table 3, Panel B and C, respectively).

Table 3 - Refugee-Immigrant Gap: Other Labour Market Outcomes

\begin{tabular}{|c|c|c|c|c|c|}
\hline & $\begin{array}{c}\text { Participation } \\
\text { (1) } \\
\end{array}$ & $\begin{array}{c}\text { Unemployment } \\
\text { (2) } \\
\end{array}$ & $\begin{array}{c}\text { Skilled } \\
\text { occupation } \\
(3) \\
\end{array}$ & $\begin{array}{c}\text { Bottom income } \\
\text { decile } \\
(4)\end{array}$ & $\begin{array}{c}\text { Top income } \\
\text { decile } \\
(5)\end{array}$ \\
\hline & \multicolumn{5}{|c|}{ Panel A - Refugees vs Migrants (Any) } \\
\hline \multirow[t]{2}{*}{ Refugee } & $-0.063 * * *$ & $0.031 * * *$ & $-0.070 * * *$ & $0.062^{* * *}$ & $-0.047 * * *$ \\
\hline & $(0.010)$ & $(0.011)$ & $(0.012)$ & $(0.021)$ & $(0.013)$ \\
\hline Observations & 67,284 & 51,405 & 44,945 & 13,431 & 13,431 \\
\hline \multirow[t]{2}{*}{ Mean Outcome - Migrants } & 0.78 & 0.14 & 0.23 & 0.16 & 0.05 \\
\hline & \multicolumn{5}{|c|}{ Panel B - Refugees vs Economic Migrants } \\
\hline \multirow[t]{2}{*}{ Refugee } & $-0.148 * * *$ & $0.055^{* * *}$ & $-0.065^{* * *}$ & $0.077^{* * *}$ & $-0.072 * * *$ \\
\hline & $(0.012)$ & $(0.013)$ & $(0.015)$ & $(0.023)$ & $(0.017)$ \\
\hline Observations & 32,376 & 27,654 & 24,476 & 7,242 & 7,242 \\
\hline \multirow[t]{2}{*}{ Mean Outcome - Migrants } & 0.89 & 0.13 & 0.14 & 0.16 & 0.04 \\
\hline & \multicolumn{5}{|c|}{ Panel C - Refugees vs Non-Economic Migrants } \\
\hline \multirow[t]{2}{*}{ Refugee } & $-0.033 * * *$ & $0.024 * *$ & $-0.066 * * *$ & $0.039 *$ & $-0.031 * *$ \\
\hline & $(0.011)$ & $(0.011)$ & $(0.013)$ & $(0.021)$ & $(0.012)$ \\
\hline Observations & 40,131 & 27,595 & 23,755 & 6,767 & 6,767 \\
\hline Mean Outcome - Migrants & 0.69 & 0.15 & 0.31 & 0.15 & 0.07 \\
\hline Host country*Year & YES & YES & YES & YES & YES \\
\hline Gender, Age, Education & YES & YES & YES & YES & YES \\
\hline Entry Cohort *Host Country FE & YES & YES & YES & YES & YES \\
\hline Entry Cohort*Source Area FE & YES & YES & YES & YES & YES \\
\hline
\end{tabular}

Notes. The table reports the coefficients for a refugee migrant dummy, estimated by linear regressions with either an unemployment dummy, a participation dummy, a skilled occupation dummy (whether employed in a high-skilled or other occupation), and a bottom and top income decile indicator as the dependent variable. In Panel A the sample comprises refugees and non-EU15 migrants (aged 25-64). The average unconditional probabilities for each outcome for non-refugee migrants are also reported in Panel A. In Panel B the sample is restricted to refugees and non-EU economic migrants, while in Panel $\mathrm{C}$ is restricted to refugees and non-EU15 non-economic migrants (i.e. those entered for family reunification/formation, study or other reasons). All specifications include destination country-observation year interaction dummies. "Gender, Age, Education" are dummy variables for gender, five-year age groups and at most upper secondary or tertiary education (with at most lower secondary education as the excluded category). "Entry cohort FE" are dummy variables for year (or groups of years) of arrival in the host country. "Host country FE" are dummies for the twenty destination countries in the sample. "Source Area" are dummy variables covering the seven major source regions. Robust standard errors in parentheses. ${ }^{* * *} \mathrm{p}<0.01,{ }^{*} * \mathrm{p}<0.05,{ }^{*} \mathrm{p}<0.1$. 


\subsection{Assimilation}

Figure 2 profiles refugee assimilation in terms of employment (A) and unemployment (B) probabilities. These estimates are obtained through direct comparison of refugees with similar migrants, conditional on individual characteristics and on fixed effects for destination countrysurvey year and area of origin. ${ }^{12}$ As expected, the gap is particularly large upon arrival: for individuals with no more than 3 years of residence in the host country, the employment probability gap is almost minus 30 percentage points, with a corresponding unemployment gap of 15 percentage points. Although this gap becomes progressively narrower with years of residence in the host country, the difference only reaches statistical insignificance after 15 years (for employment) or 9-10 years (unemployment), suggesting that refugees struggle to eliminate their initial labour market disadvantage vis-à-vis other immigrants. In Appendix Figure A 2, we display employment assimilation profiles separately for women (A) and men (B). The refugee gap tends to be smaller for women than for men: upon arrival in the host country, refugee women are 23 percentage points less likely to be employed than similar female immigrants, while the gap for men is 33 percentage points. In addition, Figure A 2 shows that women catch up with other immigrants at a faster pace than refugee men. Indeed, whereas the difference in employment probability between refugee and other immigrant women is not statistically significant after 1114 years in the host country, the refugee gap among men only disappears completely 20 years after arrival. These gender differences in assimilation profiles, however, need to be placed in the context of female non-refugee migrants having substantially worse labour market outcomes than men, as we discuss in the next section.

\footnotetext{
${ }^{12}$ Note that we use data from two cross-sections collected 6 years apart (in 2008 and 2014) and we can therefore compare the outcomes of individuals from the same entry cohort measured at different points in time simultaneously with different cohorts measured in the same year. We are thereby partially able to distinguish the effect of years since arrival from possible compositional changes across entry cohorts. Our estimated profiles, however, might be also capturing some differences in selective out-migration across migrant categories (Dustmann and Görlach 2016). If return migrants are in general negatively selected (as the North-American literature seems to suggest, while the European literature is more scarce and less clear-cut), but economic migrants outmigrate at a faster rate than refugees, then we would over-estimate refugees' integration. On the other hand, should the selection in outmigration be positive, the lower outmigration rate of refugees would imply an under-estimate of their labour market gains. Instead, if outmigration were non-selective then the differences in propensity to out migrate have no effect, and our assimilation profiles are unbiased.
} 

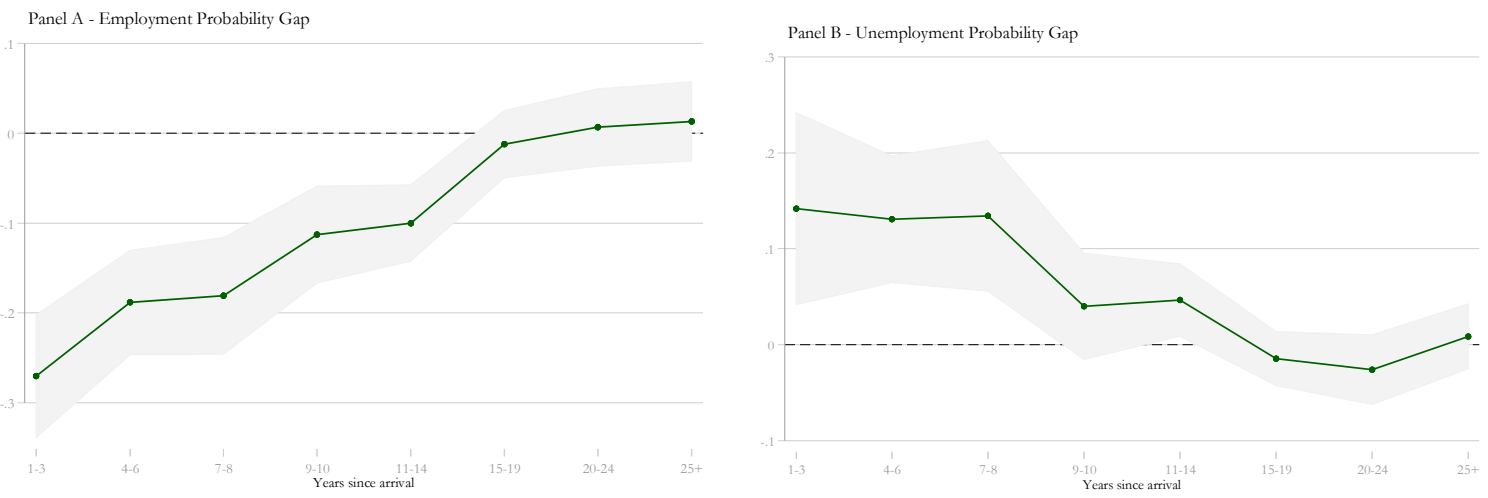

Notes. The figure graphs the evolution of the conditional gap in employment (A) and unemployment probability (B) between refugees and nonEU15 migrants by years in the host country. All regressions include age, gender, education, destination country-interview year fixed effects, and origin area fixed effects. The sample comprises non-EU15 immigrants and refugees aged $25-64$. We report 90 percent confidence intervals based on robust standard errors.

\subsection{Heterogeneity and Further Outcomes}

Heterogeneity by gender and education. In Table 4, we estimate equation (1) separately for women and men (panel A) and for tertiary and non-tertiary educated migrants (panel B). The refugee gap in employment tends to be smaller for women than for men, both in absolute value and relative to the baseline probabilities. The results in columns 1 and 2 indicate that refugee women are 5 percentage points (or 9 percent) less likely than comparable non-refugee immigrant women to be employed. In contrast, refugee men's employment rate is 11 percentage points lower than that of immigrant men with the same characteristics, a 14 percent gap relative to the baseline employment of immigrant men overall. Similar patterns hold for participation (cols. 3 and 4) and unemployment (cols. 5 and 6). Conversely, little gender difference is observable in the refugee-immigrant gap in skilled occupation probability (cols. 7 and 8 ).

As regards education, tertiary and non-tertiary educated refugees display a similar gap in employment probability (cols. 1 and 2). Non-tertiary educated refugees have instead a larger gap in participation probability (6.5 p.p., or 8.5\%) than those with tertiary education (4.6 p.p. or 5.5\%), as shown in columns 3 and 4 . Together, these two results imply that the penalty in unemployment rate is instead substantially higher for the most educated refugees (columns 5 and 6). Finally, refugees with non-tertiary education have a lower probability of being employed in a high skill occupation, not only - as expected - in absolute terms, but also relative to similarly educated migrants: the probability of having a skilled job is $37 \%$ lower for non-tertiary educated refugees 
than for other similarly educated migrants; conversely, the same gap is only $26 \%$ for refuges with tertiary education.

Table 4- Refugee-Immigrant Gaps by Gender and Education

\begin{tabular}{|c|c|c|c|c|c|c|c|c|}
\hline & \multicolumn{2}{|c|}{ Employment } & \multicolumn{2}{|c|}{ Participation } & \multicolumn{2}{|c|}{ Unemployment } & \multicolumn{2}{|c|}{ Skilled occupation } \\
\hline & (1) & (2) & (3) & (4) & $(5)$ & (6) & (7) & (8) \\
\hline & \multicolumn{8}{|c|}{ Panel A - Heterogeneity by gender } \\
\hline \multirow{3}{*}{ Refugee } & men & women & men & women & men & women & men & women \\
\hline & $-0.107^{* * *}$ & $-0.051^{* * *}$ & $-0.087^{* * *}$ & $-0.046 * * *$ & $0.041^{* * *}$ & 0.011 & $-0.067^{* * *}$ & $-0.067 * * *$ \\
\hline & $(0.015)$ & $(0.018)$ & $(0.012)$ & $(0.017)$ & $(0.014)$ & $(0.016)$ & $(0.015)$ & $(0.020)$ \\
\hline Observations & 30,763 & 36,490 & 30,763 & 36,490 & 27,269 & 24,109 & 24,051 & 20,861 \\
\hline \multirow[t]{2}{*}{ Mean Outcome - Migrants } & 0.78 & 0.57 & 0.90 & 0.67 & 0.14 & 0.15 & 0.23 & 0.22 \\
\hline & \multicolumn{8}{|c|}{ Panel B - Heterogeneity by education } \\
\hline \multirow[t]{3}{*}{ Tertiary Education: } & No & Yes & No & Yes & No & Yes & No & Yes \\
\hline & $-0.074 * * *$ & $-0.078 * * *$ & $-0.065 * * *$ & $-0.046 * *$ & $0.025^{* *}$ & $0.043^{* *}$ & $-0.037 * * *$ & $-0.143 * * *$ \\
\hline & $(0.013)$ & $(0.024)$ & $(0.012)$ & $(0.020)$ & $(0.012)$ & $(0.020)$ & $(0.012)$ & $(0.031)$ \\
\hline Observations & 51,492 & 15,754 & 51,492 & 15,754 & 38,248 & 13,115 & 33,091 & 11,811 \\
\hline Mean Outcomes - Migrants & 0.64 & 0.75 & 0.76 & 0.84 & 0.16 & 0.10 & 0.10 & 0.55 \\
\hline Host Country*Year & YES & YES & YES & YES & YES & YES & YES & YES \\
\hline Individual Controls & YES & YES & YES & YES & YES & YES & YES & YES \\
\hline Entry Cohort *Host Country FE & YES & YES & YES & YES & YES & YES & YES & YES \\
\hline Entry Cohort*Source Area FE & YES & YES & YES & YES & YES & YES & YES & YES \\
\hline
\end{tabular}

Notes. The table reports the coefficients for a refugee migrant dummy, estimated using separate linear regressions for men and women (panel A) and individuals without or with tertiary education (panel B) with either an employment dummy, a participation dummy, an unemployment dummy for a skilled occupation dummy (whether employed in a high-skilled or other occupation) as the dependent variable. The sample comprises nonEU15 immigrants and refugees aged 25-64. The baseline probabilities report the unconditional means of the outcome variables for female and male non-refugee migrants. All specifications include destination country-observation year interaction dummies. "Age and education" are dummy variables for five-year age groups and for at most upper secondary or tertiary education (with at most lower secondary education as the excluded category). "Entry cohort FE" are dummy variables for year (or groups of years) of arrival in the host country. "Host country FE" are dummies for the twenty destination countries in the sample. "Source Area" are dummy variables covering the seven major source regions. Robust standard errors in parentheses. ${ }^{* * *} \mathrm{p}<0.01,{ }^{* *} \mathrm{p}<0.05,{ }^{*} \mathrm{p}<0.1$.

Area of origin. Next, in Figure 3, we compare conditional refugee-migrant gaps in labour market outcomes across different origin areas, revealing substantial heterogeneity. ${ }^{13}$ The labour market outcomes of refugees from European countries outside the EU15 (NMS12 and other European countries) are not too dissimilar from those of comparable immigrants from the same regions, with any differences tending to be statistically insignificant. Instead, refugees from African and Asian countries - the main source areas of recent refugee inflows and arguably of those in the foreseeable future - show particularly large gaps in all the outcomes considered. Asian refugees, in particular, display the largest gaps in employment and labour market participation, while those from North Africa and the Middle East and from Sub-Saharan African countries display the largest gaps in unemployment and skilled occupation probability, respectively. Note that these results are partly

\footnotetext{
${ }^{13}$ We draw the graph by estimating separate regressions for each origin area while including controls for individual characteristics (age, gender, education) and host country-year and entry cohort-host country fixed effects.
} 
driven by the fact that more than $83 \%$ of refugees from NMS 12 countries, and $76 \%$ of those from other European countries have been in their current country of residence for more than ten years. The long period of residence implies that by time of interview, they had caught up with the other migrants' performance. Conversely, more than one third of refugees from Africa or Asia has been in the host country for no more than ten years. However, this is not enough to explain why the employment gap for these groups is larger than for refugees from other areas of origin. In fact, even African and Asian refugees who have been in the host country for more than ten years display substantial gaps in employment and participation probability relative to their non-refugee conational with the same migration seniority, which is not the case for refugees from other areas (see Figure A 3 in the Appendix).

Figure 3 - Refugee-Immigrant Gaps in Labour Market Outcomes by Area of Origin

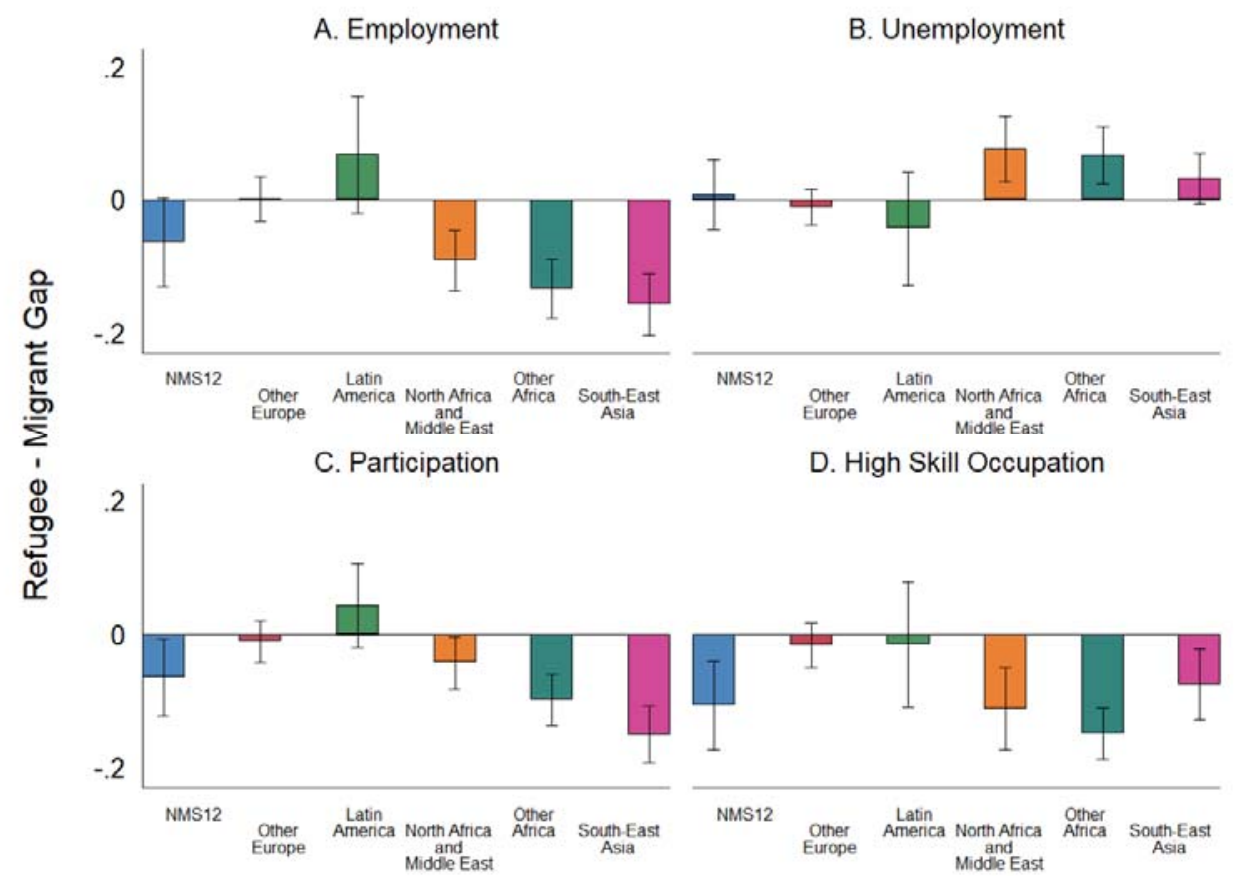

Notes. The figure illustrates the conditional refugee-migrant gaps in various labour market outcomes, together with the corresponding robust standard error-based 90 percent confidence intervals. The dependent variable is, alternatively, a dummy for whether the individual is employed (A); job hunting versus being in employment (B); employed or job hunting versus being out of the labour force (C); employed in a high-skilled occupation (D). We estimate the regressions separately for each area of origin, controlling for gender, age, education, as well as interaction between destination country dummies and observation year or entry cohort dummies. The sample comprises non-EU15 immigrants and refugees aged $25-$ 64 .

Additional outcomes. We now extend our analysis to immigrants' outcomes outside the labour market and study refugee-migrant differences in health status and social integration (as measured by host country language proficiency), and we also delve into the interplay of educational 
qualifications with labour market outcomes. Note that all variables we consider are measured at the moment of interview rather than upon entry: although they may reflect differences between refugees and other migrants on arrival, they are also the result of differences in their integration trajectories. Estimation results are reported in Table 5, for the full sample in Panel A and restricting to immigrants with at most 10 years of residence in the host country in Panel B.

Health. One likely determinant of refugees' poorer performance in the labour market is the welldocumented initial gap in physical and mental health between refugees and other migrants, which results directly from the traumatic experiences associated to forced displacement (Burnett and Peel 2001; Porter and Haslam 2005). This initial gap can either be bridged or widened by the quality of the integration process in the host country. Because the EULFS questionnaire contains no direct questions on respondents' health status, we shed light on this issue using information from other items and find evidence of large refugee gaps in health. We first consider the question on labour market status, asked of all interviewees, that includes a 'permanently disabled' category into which only 2 percent of the immigrant sample falls. Refugees, in contrast, as panel A of Table 5 shows, are 1.8 percentage points more likely to report a permanent disability than comparable immigrants (column 1). The gap is very similar even when we focus on refugees and other migrants who have been in the host country for no more than ten years (Panel B). In column 2, we consider a second health-related outcome: the reason for the job search inactivity of unemployed individuals who report no such effort in the four weeks prior to interview. We exclude from this sub-sample all those who previously self-identified as having a permanent disability. Of the remainder, approximately 10 percent answered that health or disability prevented them from job hunting, with refugees being 8.8 percentage points (almost twice as much) more likely to give this response than comparable immigrants. The refugee gap is in this case larger (both in percentage points and as percent of the mean outcome) among recent migrants, as shown in Panel B.

Host country language. Because language proficiency is one of the crucial determinants of integration in the host country (Chiswick and Miller 2014), it is rational for migrants to select a destination country based also on their own language skills and invest in learning the host country language before migrating. Forced migration, however, typically prevents refugees from carefully planning their movement and optimally choosing their destinations. We can thus expect refugees to have lower language proficiency on average upon arrival than comparable migrants, and this initial gap can then increase or decrease with years of residence in the host country. When asked 
about the obstacles to their employability in the host country, about one fifth of the immigrant respondents identified lack of proficiency in the host country language, with refugees 3.9 percentage points more likely than other migrants to make this choice (column 3, panel A), a gap that is stable - though less precisely measured - also among more recently arrived migrants (panel B). This pattern is mirrored in responses to a question on self-assessed fluency, where we find that whereas about 13 percent of the immigrant worker sample report having low proficiency in speaking the main host country language, this share increases by 3 percentage points among the refugee population (column 4, panel A). ${ }^{14}$ This gap doubles for refugees who arrived within the previous ten years (panel B), but the mean outcome for other migrants almost doubles as well, leading to a percentage refugee gap of $30 \%$ among recently arrived migrants versus $23 \%$ in the whole population.

Table 5 - Refugee-Immigrant Gaps in Health, Language and Qualifications

\begin{tabular}{|c|c|c|c|c|c|c|}
\hline & (1) & (2) & (3) & (4) & (5) & (6) \\
\hline & \multicolumn{2}{|c|}{ Health } & \multicolumn{2}{|c|}{ Host Country Language } & \multicolumn{2}{|c|}{ Qualifications } \\
\hline & $\begin{array}{l}\text { LM status: } \\
\text { permanently } \\
\text { disabled }\end{array}$ & $\begin{array}{l}\text { Reason for not } \\
\text { searching job: } \\
\text { health/disability }\end{array}$ & $\begin{array}{c}\text { Obstacle to } \\
\text { employability: } \\
\text { lack of } \\
\text { proficiency }\end{array}$ & Low proficiency & $\begin{array}{c}\text { Feeling } \\
\text { Overqualified }\end{array}$ & $\begin{array}{c}\text { Obstacle to } \\
\text { employability: } \\
\text { lack of } \\
\text { qualification } \\
\text { recognition }\end{array}$ \\
\hline & \multicolumn{6}{|c|}{ Panel A - All migrants } \\
\hline \multirow[t]{2}{*}{ Refugee } & $0.018^{* * *}$ & $0.088 * * *$ & $0.039 * * *$ & $0.031^{* *}$ & $0.095^{* * *}$ & $0.046 * *$ \\
\hline & $(0.006)$ & $(0.028)$ & $(0.014)$ & $(0.013)$ & $(0.023)$ & $(0.018)$ \\
\hline Observations & 56,878 & 10,449 & 45,109 & 30,807 & 19,570 & 16,514 \\
\hline \multirow[t]{2}{*}{ Mean Outcome - Migrants } & 0.02 & 0.1 & 0.2 & 0.13 & 0.33 & 0.13 \\
\hline & \multicolumn{6}{|c|}{ Panel B - YSM<=10 } \\
\hline \multirow[t]{2}{*}{ Refugee } & $0.014^{* *}$ & $0.120 * * *$ & $0.045^{*}$ & $0.066^{* *}$ & $0.125^{* * *}$ & $0.069 *$ \\
\hline & $(0.006)$ & $(0.038)$ & $(0.026)$ & $(0.031)$ & $(0.048)$ & $(0.037)$ \\
\hline Observations & 25,262 & 4,777 & 22,176 & 10,762 & 6,634 & 6,212 \\
\hline Mean Outcome - Migrants & 0.01 & 0.07 & 0.25 & 0.21 & 0.37 & 0.18 \\
\hline Host Country*Year & YES & YES & YES & YES & YES & YES \\
\hline Gender, Age, Education & YES & YES & YES & YES & YES & YES \\
\hline Entry Cohort*Host Country FE & YES & YES & YES & YES & YES & YES \\
\hline Entry Cohort*Source Area FE & YES & YES & YES & YES & YES & YES \\
\hline
\end{tabular}

Notes. The table reports the coefficients for a refugee migrant dummy, estimated in linear probability regressions in which the dependent variables are dummies equal to one if the respondent reports: (a) a permanent disability (column 1); (b) health or disability issues as the main reason for not actively job hunting (column 2); (c) a lack of fluency in the host country language as an obstacle to employability (column 3); (d) a "beginner or less" level of proficiency in the host country language (column 4); (e) that she/he fells overqualified for the occupation held (column 5); and (f) the lack of qualification recognition in the host country as an obstacle to employability (column 6). Outcomes (b), (e) and (f) are only available in the 2014 EU-LFS wave. The sample comprises non-EU15 immigrants aged 25-64: we use the full sample in Panel A while we restrict it to individuals with at most 10 years of residence in the host country in Panel B. All specifications include destination country-observation year interaction dummies; dummy variables for gender, five-year age groups and at most upper secondary or tertiary education (with at most lower secondary education as the excluded category); and a full set of two-way fixed effects. "Source Area FE" are dummy variables covering the seven major source regions. "Entry cohort FE" are dummy variables for year (or groups of years) of arrival in the host country. "Host country FE" are dummies for the twenty destination countries in the sample. Robust standard errors in parentheses. $* * * \mathrm{p}<0.01, * * \mathrm{p}<0.05, * \mathrm{p}<0.1$.

14 The 2014 survey directly asks immigrant interviewees to rate their fluency in speaking the main host country language on a four point scale. We use a dummy equal to one if the respondent chooses the lowest level ('beginner or less'). 
Qualifications. Finally, column (5) in Table 5 shows that employed refugees are more likely than other migrants to report that they feel overqualified for the occupation they have, and likewise column (6) demonstrates that refugees are more likely than other migrants to report the lack of qualification recognition as an obstacle to their employability (both questions are asked only in the 2014 EULFS wave). The corresponding results in Panel B indicate that problems of overqualification and of qualifications recognition are more acute among the refugees who have been less in the country. Since these results suggest that the hurdles perceived by refugees in obtaining a formal recognition of their educational qualifications are more severe than those faced by other migrants, it is natural to ask to what extent such differences can contribute to explaining the labour market penalty of refugees. The 2008 EULFS wave includes a variable reporting whether the interviewees have obtained their highest qualifications in the host country or whether they managed to establish the equivalence between their foreign qualifications and the corresponding ones in the host country. We use this variable to explore the role of qualifications in determining the observed refugee gap in employment. Our results, reported in Appendix Table A 3, indicate that immigrants with a qualification obtained in the host country and those who have established the domestic equivalence of their foreign qualifications do indeed have a higher employment probability relative to those who hold a foreign and unrecognised degree. Nevertheless, the estimated refugee gap is basically unaffected by the inclusion of these additional controls, indicating that obstacles to the recognition of foreign qualifications do not play a role in determining the refugee labour market penalty. We further test this conclusion by conditioning on a full set of field of study fixed effects (we restrict the sample to worker with tertiary education, for whom the field of study is defined): as columns 7-9 in Appendix Table A 3 show, the employment gap remains large and significant even when comparing refugees and migrants with the same level of education, field of study and recognition of their qualifications in the host country.

\section{The Role of Conditions at Arrival}

In this section, we investigate potential determinants of the observed differential socio-integration path that refugees and other migrants experience. In particular, we focus on the role of initial economic and policy conditions upon arrival in the host country. Albeit common to refugees and 
other migrants belonging to the same arrival cohort, economic conditions at the time of immigration may potentially have a stronger impact on future outcomes of the former group. We explore this conjecture in section 4.1. Even if arrived at the same time in the same country, refugees and non-refugee migrants are exposed to different policy regimes. We assess the role of migration and asylum policies faced at arrival in the host country in shaping refugees' labour market disadvantage in section 4.2. We then concentrate on a relatively common scheme in European countries - i.e. spatial Dispersal Policies of refugees - and on their impact on the refugee gap in sections 4.3 and 4.4 .

Empirically, we assess the role of arrival conditions in explaining the refugee labour market gap by including in our main estimating equation (1) a variable that measures conditions at entry in the host country $\left(W_{d T}\right)$ and its interaction with the dummy for refugee status $\left(r e f_{\text {isdTt }}\right)$. We estimate the following equation:

$y_{i s d T t}=\beta_{1} r e f_{i s d T t}+\beta_{2} W_{d T}+\beta_{3} r e f_{i s d T t} \times W_{d T}+\gamma X_{i s d T t}+\mu_{d t}+\varphi_{T}+\omega_{s}+\varepsilon_{i s d T t} \quad$ (eq.2) where the coefficients $\beta_{1}, \beta_{2}$ and $\beta_{3}$ capture the average gap in labour market outcome $y_{\text {isdTt }}$ between refugees and other migrants, the effect of initial conditions on all migrants and the differential effect of initial conditions on refugees, respectively. All other variables and fixed effects are defined as in equation (1). As in the previous part of the analysis, we then gradually include two-way fixed effects for host country-entry cohorts (which absorb the variable $W_{d T}$ ). In all regressions, standard errors are clustered at the host country level. ${ }^{15}$

\subsection{Scarring Effects of Recessions at Arrival}

A few recent studies have investigated the negative consequences for migrants of entering the host country during a recession (Aslund and Rooth, 2007; Barsbai, Steinmayr and Winter, 2020; Mask, forthcoming). We add to these findings by directly contrasting the potential scarring effects on migrants with those on refugees. Because refugee migration decisions are driven mostly by push rather than pull factors (Hatton, 2009), refugees are likely to be less responsive to the state of the host country's economy than economic migrants, increasing their chances of arriving during

\footnotetext{
${ }^{15}$ Since we have only 20 destination countries, clustering at this level may lead to inconsistent estimates of the standard errors and, therefore, to incorrect inference (Cameron et al. 2008). For this reason, in Appendix Table A 7 we also show that the statistical significance of our estimates (for both recessions and dispersal policies at entry; see sections 4.1 and 4.3, respectively) is preserved when using an alternative clustering (at the entry cohort-host country level) or wild bootstrap with clustering at the host country level.
} 
economic downturns and of permanently hindering their future labour market prospects. Over and above the potential differences in arrival timing, scarring effects from migrating in a recession may be more profound and/or persistent for refugees relative to other migrants, because the former typically start off with a substantial labour market penalty.

In order to explore the effects of economic conditions at arrival, we match each individual in our sample with a dummy variable equal to one if the host country was experiencing a recession in the year of the respondent's arrival. We define a country as being in recession if it is experiencing a negative annual growth of its real per capita GDP, which information is available for interviewees who arrived after 1980 , reducing our sample to approximately 60.5 thousand observations. ${ }^{16}$ The results of estimating equation (2) for employment probability are reported in Table 6. In panel A, we first use the full sample (columns 1-3) and we then restrict to migrants with at most ten years of residence in the host country (columns 4-6). In panel B, we change the sample of non-refugee migrants, exclusively using either economic (columns 1-3) or non-economic migrants (columns 46). For each sample, we first re-estimate the baseline refugee gap in employment (columns 1 and 4), and we then include the recession indicator (columns 2 and 5). In columns 3 and 6, we include a full set of entry cohort-host country fixed effects (absorbing any common initial shock) and we focus on the differential impact of recession on refugees by including the interaction term of the recession and refugee indicators. Estimates reported in columns 1-3 of Panel A show that arriving in a country during a recession produces persistently negative effects on labour market integration of all migrants, implying a 4.6 percentage point lower probability of being employed at the time of survey. However, controlling for these scarring effects does not reduce the estimated refugee gap, suggesting no systematic differences in the probability of arriving in the host country during a recession. ${ }^{17}$ The estimated coefficients on the interaction term, instead, are small and not significantly different from zero, pointing at no differential effect of recession on refugees with respect to comparable migrants. These results are confirmed when we restrict the sample to

\footnotetext{
${ }^{16}$ For respondents whose year of arrival is measured as a five-year interval rather than an exact year, the recession indicator equals one if there was a recession in at least half of the years in the interval considered. According to this definition, approximately 15 percent of refugees and 10 percent of migrants were exposed to a recession at arrival. Using alternative thresholds deliver qualitatively similar estimates.

${ }^{17}$ This same conclusion could be reached by observing that including entry cohort-host country fixed effects in Table 2, column 6, (and in even columns in Table 3 ) does not substantially reduce the estimated gap.
} 
migrants and refugees with lower seniority in the host country (YSM<=10; columns 4-6), a group for which scarring effects should be potentially more visible. ${ }^{18}$

Table 6 - Economic Conditions at Entry and Scarring Effects on Employment

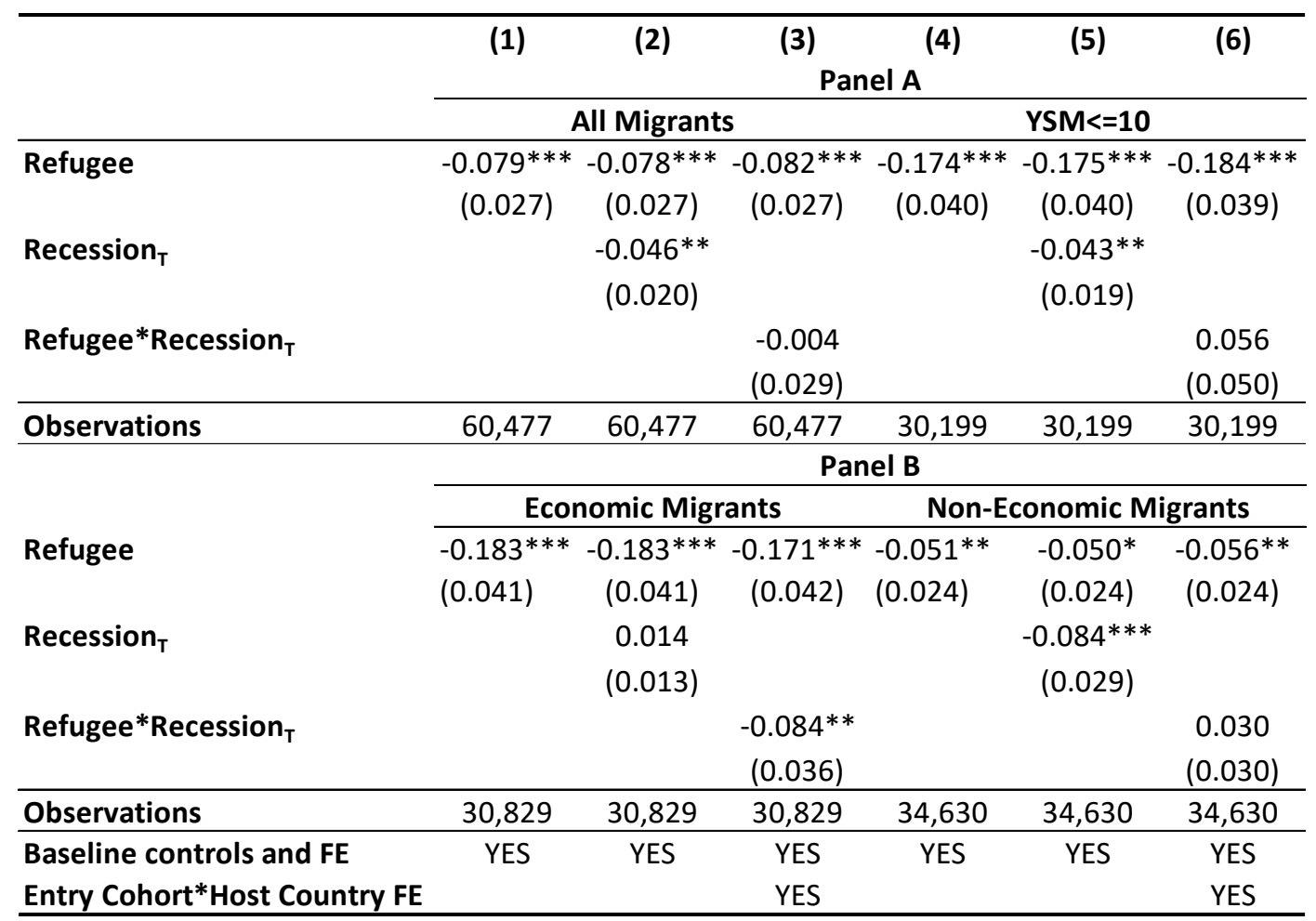

Notes. The table reports estimated coefficients from linear regressions of an employment indicator variable on a refugee migrant dummy, a recession indicator (at the time of migration, T) and their interaction. The recession dummy is equal to one for years in which real GDP per capita growth is negative, and zero otherwise. The sample comprises non-EU15 immigrants aged 25-64 who have arrived from year 1980 onward. In panel A, we first use the full sample (columns 1-3) and we then restrict to migrants with at most ten years of residence in the host country (columns 4-6). In panel B, we change the sample of non-refugee migrants, exclusively using either economic migrants (columns 1-3) or other migrants (columns 46). "Baseline controls and FE" include: destination country-observation year interaction dummies; dummy variables for gender, five-year age groups, education levels and source areas. "Entry cohort" are dummy variables for year (or groups of years) of arrival in the host country. "Host Country" are dummy variables for destination countries. Standard errors (in parentheses) are clustered at the host country level: $* * * \mathrm{p}<0.01$, $* *$ $\mathrm{p}<0.05, * \mathrm{p}<0.1$.

The lack of a differential effect of recessions on refugees that we observe may be related to the negative selection of migrants who arrive during an economic downturn. If economic migrants

${ }^{18}$ We find similar scarring effects on the probability of participation to the labour market while we fail to uncover significant effects on unemployment, probability of being in a skilled occupation and position in the income distribution. Estimates for these additional outcomes are reported in Appendix Table A 4. These estimates suggest that the employment effect we observe is primarily driven by an impact on labour market participation, similarly to the effects observed in Fasani, Frattini, Minale (2020) on refugees facing employment restrictions at entry. The results for income are in line with Guriev, Speciale and Tuccio (2019): they show that migrant wages in the formal sector did not experience downward adjustments in response to the Great Recession (while they dropped in the informal sector), with the negative shock being absorbed by the employment margin between formal and informal market. 
entering during a recession have (observable and unobservable) characteristics that are less favourable for labour market integration (as argued by Chiswick and Miller, 2002), we may fail to observe a significant difference between refugees and other migrants arrived during a recession. In addition, negative selection of the migrants who remain in the host country despite the economic downturn - which may occur if those with better outside options move back home or migrate elsewhere - may further reduce the chances of observing a differential effect of recessions on refugees. We investigate this aspect in Panel $\mathrm{B}$ of Table 6, where we contrast refugees with economic (columns 1-3) and non-economic migrants (columns 4-6). Since we expect migrants arriving for working reasons to be more responsive to economic conditions at destination than noneconomic migrants - hence more likely to select out of negative stages of the business cycle - it should be empirically harder to detect a negative effect of recessions on the former group than on the latter. At the same time, we may expect refugees to suffer substantially more from the exposure to an initial recession than economic migrants (since their larger disadvantage with respect to this group may be amplified by facing low labour demand at arrival), while the difference may be more limited with respect to non-economic migrants (who are relatively more similar in their labour market performance). Estimates in Panel B broadly confirm these conjectures. As shown in the first part of the paper (see Table 2), the refugee gap in employment is roughly three times larger relative to economic (17-18 p.p.; columns 1-3) than non-economic migrants (5-6 p.p.; columns 46). Further, when considering economic migrants, we fail to find a significant overall scarring effect of entering during a recession, but we find the differential effect of recession on refugees to be negative, sizeable ( 8 p.p.) and statistically significant (column 3 ). An opposite pattern is uncovered when comparing refugees with non-economic migrants: we observe a substantial and significant negative scarring effect of being exposed to a recession (minus 8 p.p.) but no additional negative effect on refugees. These findings suggest that the scarring effects of entering during a recession are visible for migrants that have relatively weaker labour market prospects to start with, and who are probably less able to catch up with the initial negative shock. This is consistent with evidence in the scarring literature: both Oreopoulos et al. (2012) and Altonji et al. (2016) find that college graduates with lower predicted earnings are those that suffer the harshest consequences, while Schwandt and von Wachter (2019) show that detrimental effects are concentrated among less educated workers and minorities. 


\subsection{Immigration Policies at Entry}

Refugees and other migrants are exposed to different policy regimes, at least in the initial period of their host country residence: we now direct our attention to the role played by host country migration and asylum policies in shaping refugees' labour market disadvantage. Migration and asylum policies vary across countries - and within countries over time - in such dimensions as the restrictiveness and selectivity of entry conditions, the conditionality of visas to job offers, the possibility and ease of changing employers, the conditionality of access to welfare state provisions, etc. Differences in policies faced by refugees and other migrants upon arrival in the host country may therefore shape their respective future integration trajectories and influence the gap we observe. We analyse this aspect using the migration policy indices produced by the Immigration Policies in Comparison (IMPIC) Project (Helbling et al., 2017). ${ }^{19}$ These indices, available for the period 1980-2010 only, allow measuring different migration policy dimensions. We focus, in particular, on two classes of indices measuring respectively the restrictiveness of policies that regulate entry in the country, like visa conditionality and duration (External policies) and the restrictiveness of policies for migrants who are already in the host country, like status security or labour market access conditions (Internal policies). Both indices are separately computed for economic migrants, family migrants, and refugees/asylum seekers.

Our results for the relation between migration/asylum policies at entry and current employment probability are reported in Table 7, where we focus on the most complete specification of equation (2), which includes the interaction of entry cohort with host country dummies. In column 1 we report, for reference, the estimated size of the refugee gap ( $\beta_{1}$ in equation 2$)$ on the subsample of country-years for which IMPIC data are available. In columns 2, 3 and 4 we then add, in turn, the interaction of the refugee dummy with the index for restrictiveness of external policies regarding family (column 2), economic (column 3) and asylum (column 4) migration, whereas in column 5 we simultaneously include all three policy variables. In columns 6 to 9 , we replicate the same exercise for internal policies. All indices have been standardised to have mean zero and standard deviation one, and higher values correspond to stricter policies. Notably, the inclusion of these controls does not significantly affect the size and the precision of the estimated refugee gap.

\footnotetext{
${ }^{19}$ The Immigration Policies in Comparison (IMPIC) Database is a project of the German Research Foundation that aims to provide a set quantitative index to measure immigration policies in all OECD.The data are available here: http://www.impic-project.eu/data/.
} 
Additionally, the size of the estimated coefficients on the interaction term ( $\beta_{3}$ in equation 2$)$ is small, and estimates are very imprecise. If anything, more restrictive policies for economic or family migrants (columns 3 and 6) are associated with a smaller refugee gap, which is consistent with these polices harming the employment outcomes of non-refugee migrants. Remarkably, in no case do these IMPIC-based estimates suggest that asylum policies at arrival matter for subsequent refugee labour market integration.

Table 7 - Immigration Policies and Refugee Employment gap

\begin{tabular}{|c|c|c|c|c|c|c|c|c|c|}
\hline & (1) & (2) & (3) & (4) & (5) & (6) & (7) & $(8)$ & (9) \\
\hline & & \multicolumn{4}{|c|}{ External policies } & \multicolumn{4}{|c|}{ Internal policies } \\
\hline Refugee & $\begin{array}{c}-0.079 * * * \\
(0.025)\end{array}$ & $\begin{array}{c}-0.082^{* *} \\
(0.028)\end{array}$ & $\begin{array}{c}-0.086 * * * \\
(0.025)\end{array}$ & $\begin{array}{c}-0.085^{* * *} \\
(0.021)\end{array}$ & $\begin{array}{c}-0.088^{* * *} \\
(0.022)\end{array}$ & $\begin{array}{c}-0.065^{* *} \\
(0.025)\end{array}$ & $\begin{array}{c}-0.081 * * * \\
(0.025)\end{array}$ & $\begin{array}{c}-0.073^{* *} \\
(0.026)\end{array}$ & $\begin{array}{r}-0.065^{* *} \\
(0.026)\end{array}$ \\
\hline 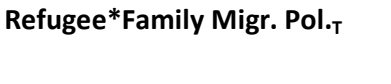 & & $\begin{array}{l}-0.015 \\
(0.037)\end{array}$ & & & $\begin{array}{l}-0.012 \\
(0.036)\end{array}$ & $\begin{array}{c}0.037^{* *} \\
(0.015)\end{array}$ & & & $\begin{array}{c}0.030 \\
(0.018)\end{array}$ \\
\hline Refugee*Economic Migr. Pol.T & & & $\begin{array}{c}0.027^{* *} \\
(0.011)\end{array}$ & & $\begin{array}{l}0.027^{*} \\
(0.013)\end{array}$ & & $\begin{array}{c}0.023 \\
(0.017)\end{array}$ & & $\begin{array}{c}0.018 \\
(0.015)\end{array}$ \\
\hline Refugee*Asylum Pol. $_{\mathrm{T}}$ & & & & $\begin{array}{c}0.012 \\
(0.024)\end{array}$ & $\begin{array}{l}-0.001 \\
(0.026)\end{array}$ & & & $\begin{array}{c}0.021 \\
(0.018)\end{array}$ & $\begin{array}{c}0.015 \\
(0.018)\end{array}$ \\
\hline Observations & 56,971 & 56,971 & 56,971 & 56,971 & 56,971 & 56,767 & 56,971 & 56,971 & 56,767 \\
\hline Baseline controls and FE & YES & YES & YES & YES & YES & YES & YES & YES & YES \\
\hline Entry Cohort*Host Country FE & YES & YES & YES & YES & YES & YES & YES & YES & YES \\
\hline
\end{tabular}

Notes. The table reports estimated coefficients from linear regressions of employment on a refugee migrant dummy and the interaction term between the refugee dummy and different indicators of immigration policy restrictiveness concerning the entry (External policies, cols. $2-5$ ) and the stay (Internal policies, cols. 6-9) of family, economic and refugee migrants in the country of destination in the year of arrival, T. The sample comprises refugees and non-EU15 immigrants aged 25-64 who have arrived in Europe from year 1980 onward. "Baseline controls and FE" include: destination country-observation year interaction dummies; dummy variables for gender, five-year age groups, education levels and source areas. "Entry cohort" are dummy variables for year (or groups of years) of arrival in the host country. . "Host Country" are dummy variables for destination countries. Standard errors (in parentheses) are clustered at the host country level: *** $\mathrm{p}<0.01, * * \mathrm{p}<0.05, * \mathrm{p}<0.1$

These findings imply that migration polices concerning the entry or the permanence of family and economic migrants do not substantially affect the refugee gap. Additionally, and perhaps more surprisingly, they also show that the overall restrictiveness of policies regulating the access and the permanence of refugees in the host country seem to play little a role in explaining the gap. However, this over-arching measure of asylum policy restrictiveness may be hiding heterogeneity in specific features of asylum policies at the time of arrival that can influence subsequent integration outcomes. We delve deeper into this aspect in the next section, where we study a specific element of asylum policy, namely, dispersal policies of asylum seekers and refugees.

\subsection{The Exposure to a Dispersal Policy}

Geographic dispersal policies (hereafter, DPs) of asylum seekers and refugees - which commonly requires that individuals seeking humanitarian protection settle in specific locations across the 
receiving country - have been adopted by several European countries in recent years. DPs go well beyond the common practice in host countries of offering some temporary accommodation in dedicated reception facilities to recently arrived asylum seekers. Although they display considerable cross country heterogeneity, DPs typically entail a reform of the national asylum policy to establish a clear legal framework for the allocation process, they may apply to asylum seekers as well as to individual with recognized refugee status, they often use social housing to accommodate the subjects for relatively long periods of time and they may impose restrictions to mobility and mechanisms that incentivize refugees to permanently settle in assigned locations. DPs have been implemented in Denmark (since 1986; Damm 2009; Azlor et al. 2020), Finland (since 1988; Andersson et al. 2010), Germany (since 1991; Bahar et al. 2019), Ireland (since 2000; Proietti and Veneri 2019), Netherlands (since 1987; Van Selm, 2000), Norway (since 1994; Bratsberg et al. forthcoming), Sweden (from 1985 to 1994; Edin et al. 2003; Åslund and Rooth 2007), Switzerland (since 1988; Couttenier et al. 2019; Martén et al. 2019) and the UK (since 2000; Bell et al. 2013). ${ }^{20}$ DPs typically pursue the aim of preventing ethnic enclave formation by scattering refugees across the country and often away from larger cities. The effects of DPs on refugees' labour market integration are a priori uncertain. If ethnic enclaves are detrimental to immigrant labour market integration, then DPs may facilitate refugees' economic success. However, being dispersed may also have negative effects. For example, not only does dispersal prevent individuals from relying on co-nationals' or relatives' networks to find a job, but limited geographic mobility reduces the chances of finding employment and good job matches. In addition, refugees are often allocated to relatively disadvantaged areas, where accommodation is cheaper but labour demand is weaker. Although several papers have exploited DPs - and their arguably exogenous allocation of refugees across different areas - to identify causal effects of hosting location characteristics on refugee outcomes, we have almost no evidence on the overall impact of being subject to these geographical restrictions versus being allowed to freely choose where to locate (with the notable exception of work by Edin et al. 2004, on Sweden).

To identify the effects of DPs on the refugee gap, we follow a similar approach to the analysis of the effects of recessions discussed in section 4.1 and re-estimate equation (2), replacing the recession indicator with a dummy that identifies entry cohorts arriving in host countries where a

\footnotetext{
${ }^{20}$ See Appendix Table A 5 for further details and references on DPs in Europe.
} 
DP was in place. ${ }^{21}$ As in all previous regressions, we condition on the usual set of controls (age, gender, education, area of origin, host country by year FE) and capture any entry condition common to both migrants and refugees (including the presence of a DP) with entry cohort-host country fixed effects. Our parameter of interest is the interaction term between the refugee dummy and the DP indicator which identifies the effect of DPs on the labour market gaps between refugees and other migrants. For identification, we exploit variation in policy exposure across entry cohorts within the same country (i.e. comparing cohorts who arrived in a specific country before and after the introduction or termination of the DPs) and within entry cohorts across countries (i.e. comparing the same arrival cohort across countries with and without active DPs). Two potential concerns regarding the causal interpretation of our estimates are worth discussing here. The first issue is that governments might choose when to introduce (or withdraw) a dispersal policy based on such considerations as economic recessions (or booms), the size of recent flows of asylum seeker and of the refugee population already in the country, the political orientation of the government in power, etc. In our case, however, this concern is taken care of by the inclusion of entry cohort-host country fixed effects as long as the effects of such conditions at entry are similar for refugees and migrants. In addition, we test the robustness of our results by allowing the impact of entry condition to produce differential effects on refugees and migrants. A second set of potential issues is the presence of systematic differences in refugees' unobservable characteristics across cohorts of arrivals in European countries and refugee self-selection into potential destination countries, which may be affected by the introduction of a dispersal policy. We deal with both types of concerns by gradually including in our specification interaction terms of the refugee dummy with entry cohort and with host country fixed effects. These interaction terms capture differences in unobservable characteristics of refugees belonging to different arrival cohorts or who migrated to different host countries which may generate spurious correlations with the exposure to DPs. Note that once both set of interaction terms are included in the specification, our regression equation is equivalent to a triple Difference-in-Difference specification.

Estimation results are reported in Table 8. We look at employment in columns 1-3 of Panel A. Over and above the usual baseline controls and set of fixed effects (individual characteristics, host

\footnotetext{
${ }^{21}$ For respondents whose year of arrival is measured as an interval rather than an exact year, the DP indicator equals one if a dispersal policy was in place in more than half of the years included in the interval. Estimates are robust to alternative options (as for instance assigning value one to the DP indicator if a dispersal policy was in place in at least one year) and are available upon request.
} 
country by survey year FE, area of origin FE) the specification in column 1 includes cohort-specific host country FE that absorb the DP coefficient entered alone. Thus, column 1 reports the coefficient on the refugee indicator as well as that on the interaction between refugee and the DP indicator. The latter coefficient indicates whether refugees who arrived when a DP was in place have a larger/smaller employment gap with migrants, compared to refugees who were not exposed to the policy. In column 2 we further enrich the model by including refugee-specific entry cohort FE that absorb the refugee dummy. Finally, column 3 adds refugee-specific host country FE, leading to the triple Diff-in-Diff specification. The size of the Refugee $* D P$ interaction coefficient is relatively stable across specifications, and in the most complete one (column 3) suggests that the refugee-migrant gap in employment is 4.5 p.p. larger for refugees who arrived when a DP was in place than for those who were not exposed to such a policy. The negative DP effect on refugee outcomes is confirmed for participation (Panel A, columns 4-6), with dispersed refugees being 5.3 p.p. less likely to be active than non-dispersed ones, while the coefficients for unemployment are small and imprecise (Panel B, columns 1-3). Contrary to the previous outcomes, the positive coefficient on the interaction term estimated for skilled occupation (Panel B, columns 4-6) suggests that DPs may reduce rather than increase refugee gaps, although these estimates are not statistically significant.

As mentioned above, our specification accounts for the potential correlation between negative initial conditions and dispersal policies - via the inclusion of entry cohort-host country fixed effects - under the assumption that the impact of initial conditions on labour market outcomes are similar for refugees and other migrants. To test whether our results are robust to allowing initial country-level shocks to have a differential impact on the refugee population vis-a-vis other migrants, we re-estimate the model while interacting conditions at arrival measured at time $\mathrm{T}-$ namely, economic conditions, asylum seekers flows, stock of refugees, and political conditions with a refugee indicator. ${ }^{22}$ As Appendix Table A 6 shows, our estimates of the dispersal policy effect are robust to accounting for the potential differential impact on refugees of the above initial conditions, even when we simultaneously control for all these variables at the same time.

\footnotetext{
${ }^{22}$ Economic conditions are measured by a recession indicator. The number of asylum applications and stock of refugees are taken from the Eurostat databases. Political conditions are measured with a left-right ideology index for the government in power (going from 0 to 10) elaborated from data provided by ParlGov (http://www.parlgov.org//).
} 
Table 8 - Dispersal Policies and Labour Market Outcomes

\begin{tabular}{|c|c|c|c|c|c|c|}
\hline & (1) & (2) & (3) & (4) & (5) & (6) \\
\hline & \multicolumn{6}{|c|}{ Panel A } \\
\hline & \multicolumn{3}{|c|}{ Employment } & \multicolumn{3}{|c|}{ Participation } \\
\hline Refugee & $\begin{array}{c}-0.059 * * * \\
(0.014)\end{array}$ & & & $\begin{array}{c}-0.046 * * \\
(0.018)\end{array}$ & & \\
\hline Refugee * Dispersal Policy & $\begin{array}{c}-0.053 \\
(0.031)\end{array}$ & $\begin{array}{c}-0.047^{* *} \\
(0.018)\end{array}$ & $\begin{array}{c}-0.045^{*} \\
(0.025)\end{array}$ & $\begin{array}{l}-0.045^{*} \\
(0.025)\end{array}$ & $\begin{array}{l}-0.040 * \\
(0.022)\end{array}$ & $\begin{array}{c}-0.053^{* * *} \\
(0.018)\end{array}$ \\
\hline \multirow[t]{3}{*}{ Observations } & 60,477 & 60,477 & 60,477 & 60,477 & 60,477 & 60,477 \\
\hline & \multicolumn{6}{|c|}{ Panel B } \\
\hline & \multicolumn{3}{|c|}{ Unemployment } & \multicolumn{3}{|c|}{ Skilled occupation } \\
\hline Refugee & $\begin{array}{c}0.026^{* *} \\
(0.012)\end{array}$ & & & $\begin{array}{c}-0.087^{* * *} \\
(0.020)\end{array}$ & & \\
\hline Refugee * Dispersal Policy & $\begin{array}{c}0.016 \\
(0.021) \\
\end{array}$ & $\begin{array}{c}0.023 \\
(0.017) \\
\end{array}$ & $\begin{array}{c}0.011 \\
(0.019)\end{array}$ & $\begin{array}{c}0.026 \\
(0.038) \\
\end{array}$ & $\begin{array}{c}0.026 \\
(0.032) \\
\end{array}$ & $\begin{array}{c}0.042 \\
(0.036) \\
\end{array}$ \\
\hline Observations & 47,274 & 47,274 & 47,274 & 41,204 & 41,204 & 41,204 \\
\hline Baseline controls and FE & YES & YES & YES & YES & YES & YES \\
\hline Entry Cohort*Host Country FE & YES & YES & YES & YES & YES & YES \\
\hline Refugee*Entry Cohort FE & & YES & YES & & YES & YES \\
\hline Refugee ${ }^{*}$ Host Country FE & & & YES & & & YES \\
\hline
\end{tabular}

Notes. The table reports estimated coefficients from linear regressions of employment (Panel A, columns 1-3), participation (Panel A, columns 46), unemployment (Panel B, columns 1-3) and skilled occupation probability (Panel B, columns 4-6) on a refugee migrant dummy and the interaction term between the refugee dummy and a Dispersal Policy indicator (which is equal to one if a DP was in place in the country of destination in the year of arrival, T). The sample comprises refugees and non-EU15 immigrants aged 25-64 who have arrived in Europe from year 1980 onward. "Baseline controls and FE": destination country-observation year interaction dummies; dummy variables for gender, five-year age groups, education levels and source areas. "Entry cohort": dummy variables for year (or groups of years) of arrival in the host country. "Host Country" are dummy variables for destination countries. Standard errors (in parentheses) are clustered at the host country level: $* * * p<0.01,{ }^{* *} \mathrm{p}<0.05,{ }^{*} \mathrm{p}<0.1$

In Table 9, we study heterogeneity of the DPs effects on refugees' employment (panel A) and participation (panel B) by years since migration, gender, and educational level. Because the mobility restrictions imposed by DPs are generally temporary, we might expect their effect to fade out with time spent in the host country as refugees gradually relocate to better areas. Indeed, the negative effects of DPs are large and strongly significant for individuals with at most 10 years of residence (column 1), while they approach zero and become statistically non-significant for refugees with longer residence duration (column 2). Further, they seem to have a larger negative effect on men compared to women, especially in participation (columns 3-4), and a similar effect on low and high educated individuals (columns 5-6).

Overall, the results from this section suggest that the detrimental effects of DPs on the labour market performance of dispersed refugees clearly prevail over their potentially positive effects we discussed at the beginning of this section. Since these effects are observed several years after arrival in European countries, there must be mechanisms that generate persistence in DPs well beyond the initial allocation. We explore the role of geographical dispersion in the next section. 
Table 9 - Heterogeneity in Dispersal Policy Effects

\begin{tabular}{|c|c|c|c|c|c|c|}
\hline & $\begin{array}{c}\text { YSM 0-10 } \\
\text { (1) }\end{array}$ & $\begin{array}{c}\text { YSM >10 } \\
(2)\end{array}$ & $\begin{array}{c}\text { Men } \\
(3) \\
\end{array}$ & $\begin{array}{c}\text { Women } \\
(4)\end{array}$ & $\begin{array}{c}\text { Tertiary } \\
\text { education } \\
(5) \\
\end{array}$ & $\begin{array}{c}\text { Lower/Upper } \\
\text { sec. educ. } \\
(6)\end{array}$ \\
\hline & \multicolumn{6}{|c|}{ Panel A - Employment } \\
\hline Refugee $^{*}$ Dispersal Policy & $\begin{array}{c}-0.175^{* * *} \\
(0.056)\end{array}$ & $\begin{array}{c}0.022 \\
(0.050)\end{array}$ & $\begin{array}{l}-0.047 \\
(0.030) \\
\end{array}$ & $\begin{array}{c}-0.031 \\
(0.051) \\
\end{array}$ & $\begin{array}{l}-0.036 \\
(0.040)\end{array}$ & $\begin{array}{c}-0.058 \\
(0.038) \\
\end{array}$ \\
\hline \multirow[b]{2}{*}{ Refugee $^{*}$ Dispersal Policy } & \multicolumn{6}{|c|}{ Panel B - Participation } \\
\hline & $\begin{array}{c}-0.290 * * * \\
(0.073)\end{array}$ & $\begin{array}{c}0.015 \\
(0.032)\end{array}$ & $\begin{array}{c}-0.060 * * * \\
(0.016)\end{array}$ & $\begin{array}{l}-0.034 \\
(0.041)\end{array}$ & $\begin{array}{c}-0.053^{* *} \\
(0.024)\end{array}$ & $\begin{array}{c}-0.058^{* *} \\
(0.025)\end{array}$ \\
\hline Baseline controls and FE & YES & YES & YES & YES & YES & YES \\
\hline Entry Cohort*HostCountry FE & YES & YES & YES & YES & YES & YES \\
\hline Refugee*Entry Cohort FE & YES & YES & YES & YES & YES & YES \\
\hline Refugee ${ }^{*}$ Host Country FE & YES & YES & YES & YES & YES & YES \\
\hline Observations & 30,199 & 30,278 & 27,538 & 32,935 & 14,176 & 46,291 \\
\hline
\end{tabular}

Notes. The table assess the heterogeneity of the Dispersal Policy effect on employment and participation for individuals with different number years of experience in the destination country ( 0 to 10 years since migration vs more than 10 years; column 1-2), gender (column 3-4), and educational level (columns 5-6). The table reports the estimated coefficients for the interaction between a refugee migrant dummy and an indicator for a DP being active in the destination country at the migrant's time of arrival (T). The sample comprises non-EU15 immigrants aged 25-64 who have arrived in Europe from year 1980 onward. "Baseline controls and FE" include: destination country-observation year interaction dummies; dummy variables for gender, five-year age groups, education levels and source areas. "Entry cohort" are dummy variables for year (or groups of years) of arrival in the host country. "Host Country" are dummy variables for destination countries. Standard errors (in parentheses) are clustered at the host country level: $* * * \mathrm{p}<0.01, * * \mathrm{p}<0.05, * \mathrm{p}<0.1$.

\subsection{The Geographical Distribution of Dispersed Refugees}

By altering refugees' geographical distribution, DPs might affect their labour market outcomes if dispersal areas differ systematically in characteristics that favour economic integration with respect to the areas that refugees would have chosen in the absence of the policy. Although we cannot observe this counterfactual distribution, we can compare the residential choices of dispersed and non-dispersed refugees and contrast them with those of other migrants in our sample in order to learn about the spatial effects of the DPs in the medium-long run. We investigate this issue by exploiting residential data included in the EULFS. In particular, we know the degree of urbanisation of the area of current residence for all respondents, while we use the region identifier (NUTS1 or NUTS2 level; available for the majority of host countries in our sample) to match individuals with regional characteristics such as population density, GDP per capita, whether the region hosts the country capital, share of population with tertiary education and immigrant share. ${ }^{23}$ In Table 10, we perform two empirical tests. First, in order to assess the role of geography in

\footnotetext{
${ }^{23}$ The degree of urbanisation (degurba) variable in the EULFS classifies areas into three groups - cities, towns and rural areas - according to their population density. Information on the region of residence (NUTS1 or NUTS2) is available for all countries in our sample except Cyprus, Luxembourg and Netherlands, leaving us with a sample of approximately 50 thousand migrants.
} 
explaining some of the observed refugee-migrant gap in labour outcomes, we re-estimate our main regression equation with geographical variables as outcomes and study whether refugees differ systematically from other migrants in their residential choices (Table 9, odd columns). Second, to study whether the exposure to DPs generates persistent differences in residential patterns, we estimate the same specifications presented in Table 8 for geographical variables (Table 10, even columns). In both cases, we consider four outcomes: probability of living in urban areas (columns 1-2), regional population density (columns 3-4), regional GDP per capita (columns 5-6), probability of living in the capital region (columns 7-8), share of active population with tertiary education (columns 9-10) and share of non-EU foreign born population (columns 11-12). We use the full estimation sample in Panel A, while we restrict it to migrants with less than 10 years of residence in Panel B. Estimates in odd columns imply that, on average, refugees' residential choices do not systematically differ from those of other migrants (Panel A), although some sizeable differences are found for the sample of more recently arrived migrants (Panel B). In particular, the negative coefficients in column 5 of Panel B suggest that refugees with at most 10 years of residence in host countries are more likely to live in relatively poorer regions (with approximately 1.5 thousand Euros lower GDP per capita, with respect to an average of 32.2 thousand). These findings suggest that refugees may suffer from a disadvantage in making their initial residential decisions but they then converge to the pattern observed for other migrants, leaving little role to geography in explaining the refugee-migrants gap in labour market outcomes we discussed in section $3 .{ }^{24}$ Our results for the effects of DPs on refugees' residential choices - reported in even columns of Table 9 - are instead stronger and more conclusive. Refugees who were exposed to a DP at the time of their arrival in the host country currently reside in regions that are less densely populated (columns 2 and 4), have a lower GDP per capita (column 6), are less likely to host the capital city (column 8), have a lower share of active population with tertiary education (column 8) and host a smaller share of immigrant population (column 12). As expected, the effects are larger in magnitude and more significant when we restrict the sample to migrants and refugees with at most ten years of residence in the host country (Panel B), since dispersed refugees in this population had relatively less time to counteract the initial allocation through internal mobility.

\footnotetext{
${ }^{24}$ Indeed, estimating equation (1) for employment and other labour market variables with the inclusion of a full set of regional fixed effects only marginally reduces the refugee-immigrant gap. Results can be provided upon request.
} 
Figure 4 provides a visual impression of the effect of DPs on the regional distribution of refugees in host countries. For the subset of countries that have adopted a DP and for which the information on respondents' region of residence is available in the EULFS (i.e. Finland, Germany, Norway, Sweden, Switzerland and UK), we can compute the shares of dispersed and non-dispersed refugees residing in each region and plot them against the regional GDP per capita. Figure 4 shows a clear positive gradient in all countries (with the partial exception of Switzerland, where the relationship is almost flat) for both groups of refugees, suggesting that they all tend to cluster in wealthier regions. In all countries, however, the gradient is remarkably steeper for non-dispersed refugees, implying that the DPs permanently hinder the ability of affected refugees to move into areas that offer better economic opportunities.

Figure 4 - Geographical Distribution of Refugees and Regional GDP pc, by Dispersal Status

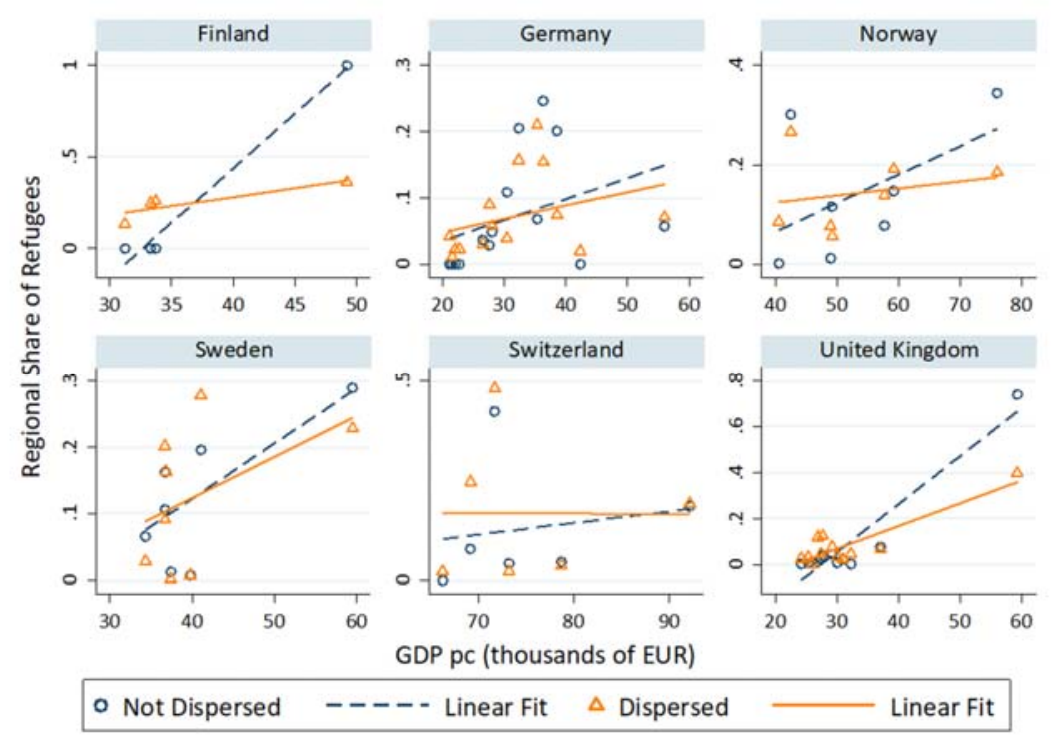

Notes. The figure plots the shares of dispersed and non-dispersed refugees residing in each region against the regional GDP per capita (in current market prices; source: Eurostat and Swiss Federal Statistical Office). We produce a graph for each host country in the subset of countries that have adopted a DP and for which the information on respondents' region of residence is available in the EULFS. 
Table 10 - Geography and Dispersal Policies

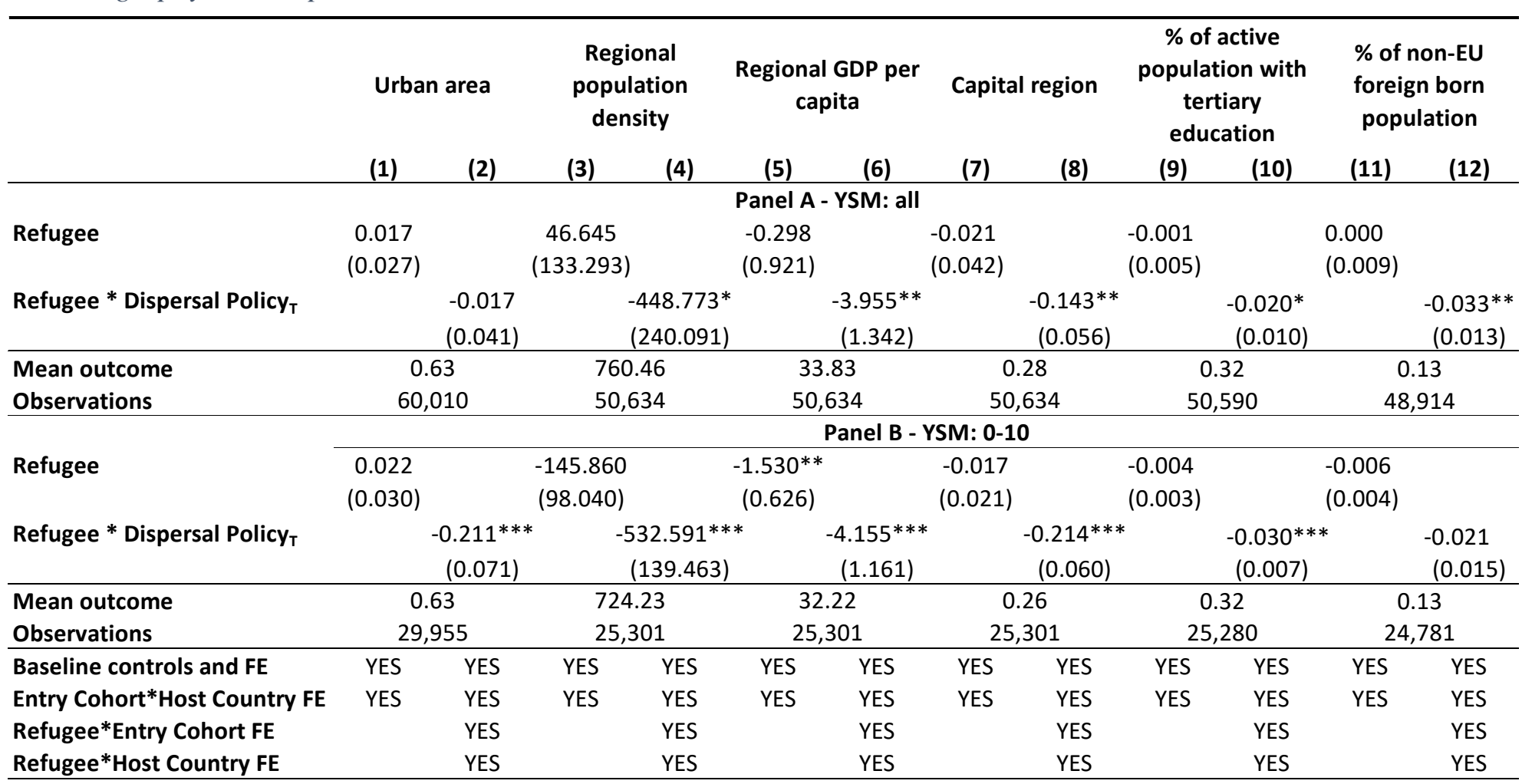

Notes. The table reports estimated coefficients from linear regressions of regional characteristics on a refugee dummy (odd columns) and on the interaction of the refugee dummy with a Dispersal Policy indicator (even columns). The DP dummy is equal to one if a DP was in place in the country of destination in the year of arrival (T). The outcomes are: probability of living in urban areas (columns 1-2), regional population density (columns 3-4), regional GDP per capita (measured in in thousands of euros, at current prices; columns 5-6), probability of living in the capital region (columns 7-8), share of active population with tertiary education (columns 9-10) and share of non-EU foreign born population (columns 11-12). We use the full estimation sample in Panel A, while in Panel B we restrict it to migrants with less than 10 years of residence. The sample comprises non-EU15 immigrants aged 25-64 who have arrived in Europe from year 1980 onward. "Baseline controls and FE" include: destination country-observation year interaction dummies; dummy variables for gender, five-year age groups, education levels and source areas. "Entry cohort" are dummy variables for year (or groups of years) of arrival in the host country. . "Host Country" are dummy variables for destination countries. Standard errors (in parentheses) are clustered at the host country level: *** $p<0.01, * * p<0.05, * \mathrm{p}<0.1$ 
Migrants are characterized by high mobility and, when left free to choose where to settle, they typically choose locations that maximise their economic and social inclusion. Our estimates suggest that DPs impose important constraints on these choices for exposed refugees, persistently affecting their residential patterns and inducing them to reside in areas characterized by less favourable conditions. These results speak directly to recent work on refugee matching that has discussed ways to improve both the international refugee match, i.e. the allocation of refugees across countries (Fernández-Huertas Moraga and Rapoport, 2014 and 2015; Jones and Teytelboym, 2017) and the local refugee match, i.e. the allocation across locations within any given country (Bansak et al., 2018; Trapp et al., 2018). These studies have discussed how the matching could be based on preferences elicited from refugees and hosting countries (or communities) or determined by the objective of maximizing specific refugees' outcomes, such as their employment. Recent work by Bansak et al. (2018) and Trapp et al. (2018), in particular, show that using outcome optimization algorithms would produce large employment gains. We believe that our findings on the effects of DPs contribute novel evidence to both the preference-based and the outcome-optimization allocation strategies. The fact that, on average, we fail to observe any significant difference in the geographical distribution of migrants and refugees across areas, implies that residential choices are homogenous across the two groups, strongly suggesting that they have similar preference and take into account overlapping sets of local variables in making their decisions. This implies that allowing refugees' preferences to play a role in their allocation would most likely improve the final outcome with respect to the status quo. Further, we find that a difference in residential locations is observed only when the dispersal policy artificially creates a wedge between affected and non-affected refugees, with the former group being placed in less favourable areas than the latter. Combined with the previous finding, this result implies that one could improve the allocation of refugees by simply removing the DP and rely on refugee's preferences to determine their distribution. Alternatively, if the policy has to be kept in place - for instance, because governments still find it desirable to avoid excessive concentration of foreign born individuals in the same areas - locations could be selected in order to maximize employment prospects of dispersed refugees. 


\section{Conclusions}

The major refugee crisis recently experienced in Europe has positioned concerns about the successful integration of asylum seekers into host societies and their labour markets at the centre of the current economic and political debate. Our findings raise serious concerns about the future economic integration of asylum seekers who arrived in EU countries during the last few years. The fact that the so-called European refugee crisis was characterized by a sudden and vast inflow of individuals in a relatively short time span will probably add to the challenges with which host countries must deal. Part of the difficulties faced by refugees trying to integrate into receiving societies are inherently associated with the forced nature of their migration and the violence they experienced. What happens next, however, is at least partially in the hands of host governments. If removing the barriers that prevent all migrants from rapidly assimilating to the employment and earning profiles of natives falls well beyond the scope of host-countries asylum policies, a more realistic and viable target could be that of ensuring that refugees assimilate at least as fast as other comparable migrants. Our analysis suggests that governments may negatively influence the speed and quality of refugee integration by implementing potentially suboptimal and counterproductive asylum policies. One reason for such implementation is the important trade-off these governments face when making decisions in this policy area. That is, whenever they aim to reduce immigrant inflows by making their policies more restrictive and their countries less attractive (for instance, by subjecting refugees to dispersal policies), they also tend to affect existing stocks of immigrants and/or refugees, potentially harming their future prospects for socio-economic integration. At the same time, short-term political considerations may induce policy makers to favour measures that minimize immediate costs rather than maximizing long-run benefits, leading to potential underinvestment in refugee integration. Dispersing asylum claimants and refugees in relatively deprived areas, for instance, may be justified by immediate budget savings from lower accommodation costs, but these savings should be weighed against the negative effects of refugee dispersal on their future labour market integration. Hence, an additional challenge posed by the current refugee crisis is how to overcome myopia in designing European asylum policy. 


\section{References}

Altonji Joseph G., Lisa B. Kahn, and Jamin D. Speer. 2016. Cashier or Consultant? Entry Labor Market Conditions, Field of Study, and Career Success, Journal of Labor Economics, 34(S1), S361-S401.

Andersson, R., Dhalmann, H., Holmquist, E., Kauppinen, T. M., Turner, L. M., Skifter Andersen, H. et al., 2010. Immigration, housing and segregation in the Nordic welfare states, Helsinki: Department of Geosciences and Geography, University of Helsinki.

Åslund, Olof, and Rooth, Dan-Olof, 2007. Do when and where matter? Initial labour market conditions and immigrant earnings. Economic Journal, 117(518), 422-448.

Azlor, Luz, Damm, Anna Pill and Schultz-Nielsen, Marie Louise, 2020. Local labour demand and immigrant employment. Labour Economics, In Press.

Bahar, D., Özgüzel, C., Hauptmann, A. and Rapoport, H., 2019. Migration and post-conflict reconstruction: The effect of returning refugees on export performance in the former Yugoslavia. IZA DP N.12412.

Bansak, Kirk, Jeremy Ferwerda, Jens Hainmueller, Andrea Dillion, Dominik Hangartner, Duncan Lawrence, and Jeremy Weinstein. 2018. Improving refugee integration through data-driven algorithmic assignment. Science, 359(6373), 325-329

Barsbai T., A. Steinmayr, and C. Winter (2020) Immigrating into a Recession, mimeo

Battisti, M., Peri, G., \& Romiti, A., 2016. Dynamic effects of Co-Ethnic networks on immigrants' economic success. NBER Working Papers 22389. National Bureau of Economic Research.

Beaman, Lori A., 2012. Social networks and the dynamics of labour market outcomes: evidence from refugees resettled in the US. Review of Economic Studies, 79(1), 128-161.

Becker, Sascha O. and Ferrara, Andreas, 2019. Consequences of forced migration: A survey of recent findings. Labour Economics, 59(C), 1-16

Bell, Brian, Fasani, Francesco, Machin, Stephen, 2013. Crime and immigration: evidence from large immigrant waves. Review of Economics and Statistics, 21(3), 1278-1290.

Bevelander, Pieter, 2016. Integrating refugees into labor markets. IZA World of Labor, 269.

Bevelander, Pieter, Pendakur Ravi, 2014. The labour market integration of refugee and family reunion immigrants: a comparison of outcomes in Canada and Sweden. Journal of Ethnic and Migration Studies, 40(5), 689-709. 
Borjas, G.J.. 1999 The economic analysis of immigration, in O.C. Ashenfelter and D. Card (eds), Handbook of Labor Economics 3A, 1697-1760, Elsevier.

Bratsberg, Bernt, Raaum, Oddbjorn, Roed, Knut, 2014. Immigrants, labour market performance and social insurance. Economic Journal, 24(580), 644-683.

Bratsberg, Bernt, Ferwerda, Jeremy, Finseraas, Henning and Kotsadam, Andreas. (forthcoming). How Settlement Locations and Local Networks Influence Immigrant Political Integration, American Journal of Political Science.

Brell, Courtney, Christian Dustmann, and Ian Preston. 2020. The Labor Market Integration of Refugee Migrants in High-Income Countries. Journal of Economic Perspectives, 34 (1): 94121.

Burnett, Angela, Peel, Michael, 2001. Health needs of asylum seekers and refugees. BMJ, $322(7285), 544-547$.

Cameron, A. Colin, Jonah B. Gelbach, and Douglas L. Miller (2008). "Bootstrap-Based Improvements for Inference with Clustered Errors.” The Review of Economics and Statistics, $90(3), 414-427$.

Chiswick, B. R. and Miller, P. W. 2002. Immigrant earnings: language skills, lingusitic concentrations and the business cycle. Journal of Population Economics, 15: 31-57.

Chiswick, Barry R., Miller, Paul W., 2014. International migration and the economics of language. IZA Discussion Papers 7880.

Cortes, Kalena E., 2004. Are refugees different from economic immigrants? Some empirical evidence on the heterogeneity of immigrant groups in the United States. Review of Economics and Statistics, 86(2), 465-480.

Couttenier, Mathieu, Veronica Petrencu, Dominic Rohner, and Mathias Thoenig. 2019. The Violent Legacy of Conflict: Evidence on Asylum Seekers, Crime, and Public Policy in Switzerland. American Economic Review, 109 (12): 4378-4425.

Dagnelie, Olivier, Mayda, Anna M., and Maystadt, Jean-Francois, 2019. The labor market integration of refugees in the United States: Do entrepreneurs in the network help? European Economic Review, 111, 257-272.

Damm, Anna Piil, 2009. Ethnic enclaves and immigrant labor market outcomes: quasiexperimental evidence. Journal of Labor Economics, 27(2), 281-314. 
Damm, Anna Piil and Dustmann, Christian. 2014. Does Growing Up in a High Crime Neighborhood Affect Youth Criminal Behavior? American Economic Review, 104(6), 18061832.

Dustmann, Christian and Görlach, Joseph-Simon. 2016. Estimating immigrant earnings profiles when migrations are temporary, Labour Economics, 41, 1-8

Dustmann, Christian, Vasiljeva, Kristine and Damm, Anna Piil., 2019. Refugee migration and electoral outcomes. The Review of Economic Studies, 86(5), 2035-2091.

Dustmann, Christian, Fasani, Francesco, Frattini, Tommaso, Minale, Luigi, Schönberg, Uta, 2017. On the economics and politics of refugee migration. Economic Policy, 32(91), 497-550.

Edin, Per-Anders, Fredriksson, Peter, Åslund, Olaf, 2003. Ethnic enclaves and the economic success of immigrants: evidence from a natural experiment. Quarterly Journal of Economics, 118(1), 329-357.

Edin, Per-Anders, Fredriksson, Peter, Åslund, Olaf, 2004. Settlement policies and the economic success of immigrants. Journal of Population Economics. 17, 133-155.

Fasani Francesco \& Tommaso Frattini \& Luigi Minale, 2020. Lift the Ban? Initial Employment Restrictions and Refugee Labour Market Outcomes, CReAM Discussion Paper Series 2010, Centre for Research and Analysis of Migration (CReAM), Department of Economics, University College London.

Fernández-Huertas Moraga, J. F.-H. and Rapoport, H. 2014. Tradable immigration quotas. Journal of Public Economics, 115:94-108,.

Fernández-Huertas Moraga, Jesùs, Rapoport, Hillel, 2015. Tradable refugee-admission quotas and EU asylum policy. CESifo Economic Studies, 61, 638-72.

Foged, Mette, and Giovanni Peri, 2016. Immigrants' Effect on Native Workers: New Analysis on Longitudinal Data. American Economic Journal: Applied Economics, 8 (2), 1-34.

Gelbach, Jonah B., 2016. When do covariates matter? And which ones, and how much? Journal of Labor Economics, 34(2), 509-543.

Godøy, Anna, 2017. Local labor markets and earnings of refugee immigrants, Empirical Economics, 52(1), 31-58.

Guriev Sergei \& Biagio Speciale \& Michele Tuccio, 2019. "How do Regulated and Unregulated Labor Markets Respond to Shocks? Evidence from Immigrants During the Great Recession," 
Journal of Law, Economics, and Organization, Oxford University Press, vol. 35(1), pages 3776.

Hainmueller, Jens, Hangartner, Dominik, Lawrence, Duncan, 2016. When lives are put on hold: lengthy asylum processes decrease employment among refugees. Science Advances, 2(8).

Hatton Timothy J., 2009. The rise and fall of asylum: what happened and why? Economic Journal, 119(535), 183-213.

Hatton, Timothy J., 2017. Refugees and asylum seekers, the crisis in Europe and the future of policy, Economic Policy, 32(91), 447-496.

Jones, Will and Alexander Teytelboym, 2017, The International Refugee Match: A System that Respects Refugees’ Preferences and the Priorities of States, Refugee Survey Quarterly, 36(2), 84-109.

Kahn, Lisa B. 2010. The long-term labor market consequences of graduating from college in a bad economy. Labour Economics 17(2), 303-316.

Kerr, Sari Pekkala and Kerr, William R. 2011. Economic Impacts of Immigration: A Survey, NBER Working Papers 16736, National Bureau of Economic Research.

Luik, Marc-André, Emilsson, Henrik, Bevelander Pieter, 2016. Explaining the male nativeimmigrant employment gap in Sweden: the role of human capital and migrant categories. IZA DP No. 9943.

Martén, Linna, Hainmueller, Jens and Hangartner, Dominik. 2019. Ethnic networks can foster the economic integration of refugees. Proceedings of the National Academy of Sciences, 116 (33) 16280-16285.

Oreopoulos, Philip, Von Wachter, Till, Heisz, Andrew, 2012. The short- and long-term career effects of graduating in a recession. American Economic Journal: Appl. Econ., 4(1), 1-29.

Porter, Matthew, Haslam, Nick, 2005. Pre-displacement and post-displacement factors associated with mental health of refugees and internally displaced persons: a meta-analysis. (JAMA) Journal of the American Medical Association, 294(5), 602-612.

Proietti, P. and Veneri, P. forthcoming. The Location of Hosted Asylum Seekers in OECD Regions and Cities. Journal of Refugee Studies.

Roodman, David, James G. MacKinnon, Morten Ørregaard Nielsen, and Matthew D. Webb (2019). Fast and wild: Bootstrap inference in Stata using boottest. Stata Journal, 19(1), 4-60. 
Ruiz, I. and Vargas-Silva, C., 2018. Differences in labour market outcomes between natives, refugees and other migrants in the UK. Journal of Economic Geography, 18(4), pp.855-885.

Sarvimäki, Matti, 2017. Labor market integration of refugees in Finland. Nordic Economic Policy Review, 7(1): 91-114.

Schwandt, Hannes, and Till Von Wachter (2019). "Unlucky cohorts: Estimating the long-term effects of entering the labor market in a recession in large cross-sectional data sets." Journal of Labor Economics, 37, 161-198.

Trapp, Andrew C., Teytelboym, Alexander, Martinello, Alessandro, Andersson, Tommy and Ahani, Narges, 2018. Placement Optimization in Refugee Resettlement, WP 23, Lund University, Department of Economics.

Van Selm, Joan. 2000. Asylum in the Netherlands: A Hazy Shade of Purple. Journal of Refugee Studies, 13(1), 74-90 


\section{Appendix Figures}

Figure A 1 - Employment and Unemployment Gaps with Respect to Natives, by Years Since Arrival

Panel A - Employment: Probability Gap

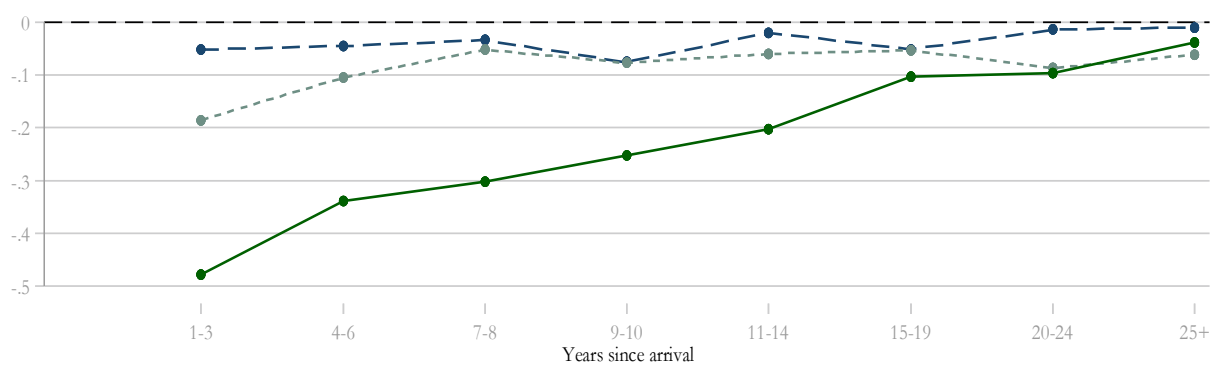

Panel B - Unemployment: Probability Gap

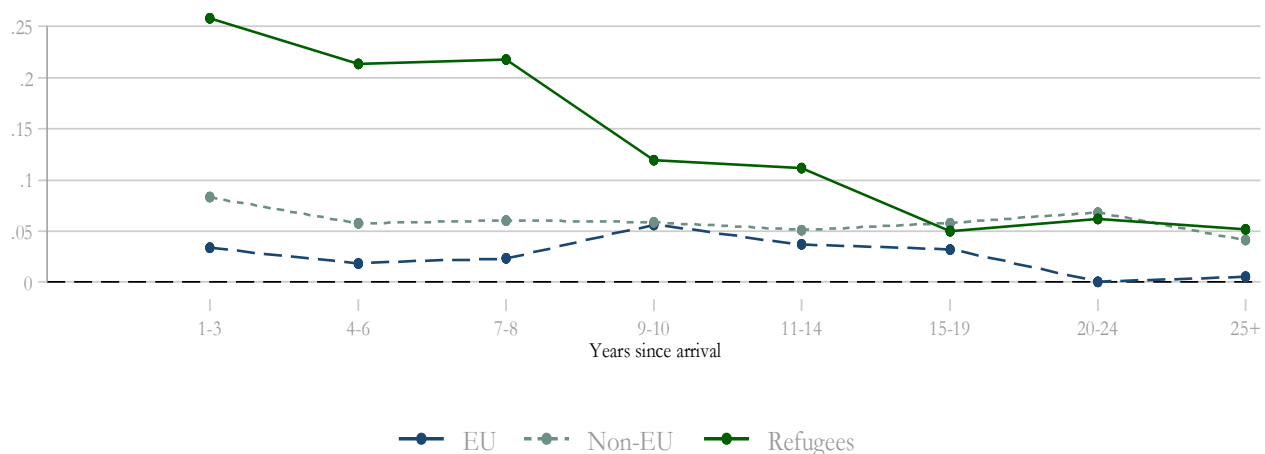

Notes. The figure outlines the evolution of the percentage point difference in employment probability (panel A) and unemployment probability (panel B) between natives and EU migrants (blue circles), non-EU migrants (red diamonds) and refugees (green triangles) by years in the host country. The estimates are conditional on age, gender and education plus destination country-interview year fixed effects. The sample comprises individuals aged 25-64, who are not in full-time education or military service; sample size: 982,970 observations in Panel A and 750,273 observations in Panel B.

Figure A 2 - Female versus Male Refugee-Immigrant Employment Gaps by Years Since Arrival

Panel A - Employment Probability Gap - Women

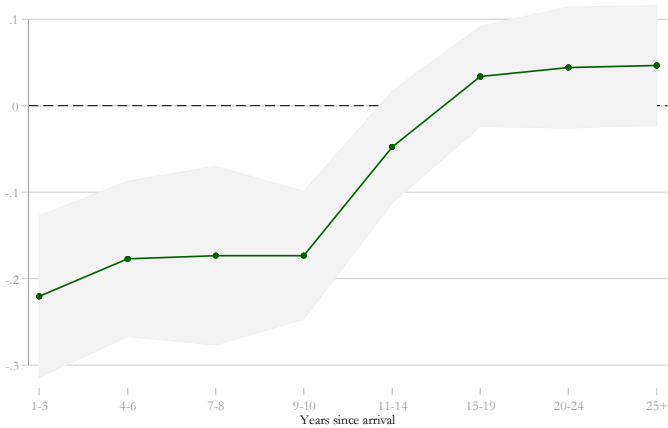

Panel B - Employment Probability Gap - Men

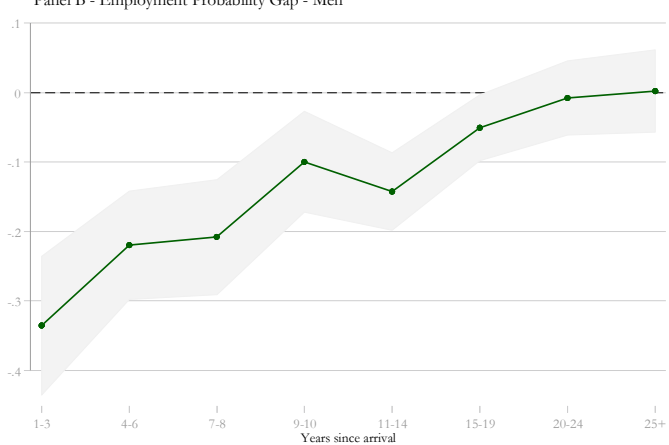

Notes. The figure illustrates the evolution of the conditional gap in employment probability between female (panel A) and male (panel B) refugees and non-EU15 migrants by years in the host country. All regressions include age, education, destination country-interview year fixed effects, and origin area fixed effects. The sample comprises non-EU15 immigrants aged 25-64. The shaded areas report 90 percent confidence intervals based on robust standard errors. 
Figure A 3 Refugee-Immigrant Gaps in Labour Market Outcomes by Area of Origin

\section{Panel A - Ten years or less since migration}

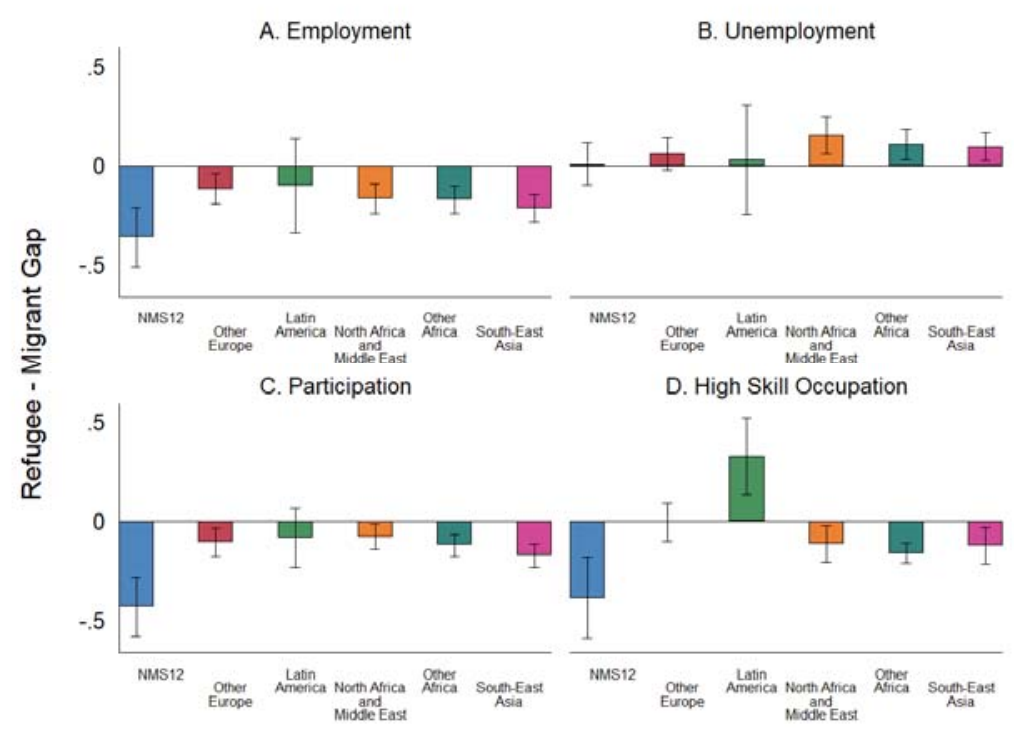

Panel B - More than ten years since migration

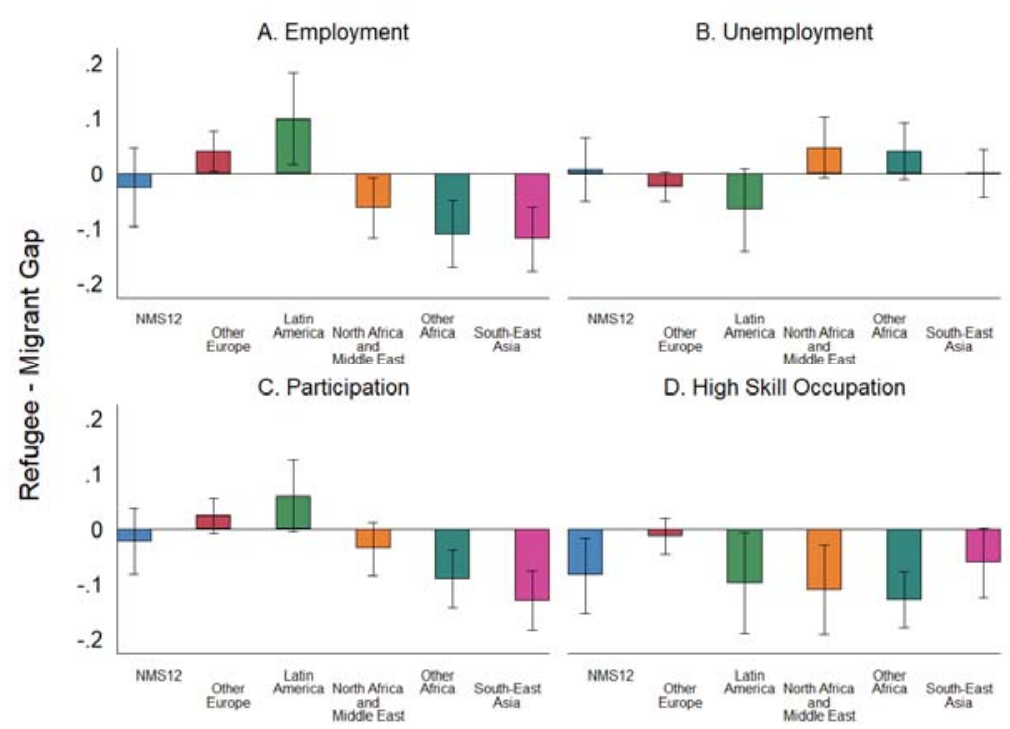

Notes. The figure illustrates the conditional refugee-migrant gaps in various labour market outcomes, together with the corresponding robust standard error-based 90 percent confidence intervals. Panel A (B) reports gaps between refugees and other migrants who have been in the country for no more (more) than ten years. The dependent variable is, alternatively, a dummy for whether the individual is employed (A); job hunting versus being in employment (B); employed or job hunting versus being out of the labour force (C); employed in a high-skilled occupation (D). We estimate the regressions separately for each area of origin, controlling for gender, age, education, as well as interaction between destination country dummies and observation year or entry cohort dummies. The sample comprises non-EU15 immigrants and refugees aged 25-64. 


\section{Appendix Tables}

Table A 1 - Sample of Immigrants and Refugees by Host Country

\begin{tabular}{lccc}
\hline \hline & Refugees & $\begin{array}{c}\text { Other } \\
\text { Migrants }\end{array}$ & Total \\
\hline AT & 625 & 3,707 & 4,332 \\
BE & 373 & 2,096 & 2,469 \\
CH & 47 & 1,150 & 1,197 \\
CY & 49 & 692 & 741 \\
DE & 258 & 1,282 & 1,540 \\
ES & 52 & 10,400 & 10,452 \\
FI & 43 & 325 & 368 \\
FR & 207 & 3,411 & 3,618 \\
GR & 438 & 4,608 & 5,046 \\
HR & 96 & 408 & 504 \\
HU & 32 & 1058 & 1,090 \\
IE & 66 & 1,912 & 1,978 \\
IT & 72 & 11,844 & 11,916 \\
LU & 59 & 959 & 1,018 \\
NL & 944 & 5,620 & 6,564 \\
NO & 278 & 1,085 & 1,363 \\
PT & 52 & 1,362 & 1,414 \\
SE & 940 & 1,802 & 2,742 \\
SI & 27 & 700 & 727 \\
UK & 565 & 7,640 & 8,205 \\
\hline Total & 5,223 & 62,061 & 67,284 \\
\hline \hline
\end{tabular}

Notes. The table reports the number of refugees (col. 1) and non-EU15 migrants (col. 2) in our estimating sample by destination country. The sample comprises all individuals aged 25-64 not in full-time education or military service.

Table A 2 - Employment Refugee Gap: Gelbach Decomposition

\begin{tabular}{lccc}
\hline & \multicolumn{2}{c}{ Specification } & Difference: \\
& Base & Full & Base-Full \\
\hline Refugee gap & -0.064 & -0.076 & 0.012 \\
& $(0.012)$ & $(0.011)$ & $(-0.004)$ \\
\hline $\begin{array}{l}\text { Controls: } \\
\text { Gender and Age }\end{array}$ & NO & YES & 0.029 \\
& & & $(0.003)$ \\
Education & NO & YES & -0.006 \\
& & & $(0.002)$ \\
Source Area FE & NO & YES & -0.021 \\
& & & $(0.002)$ \\
Entry Cohort FE & NO & YES & 0.010 \\
& & & $(0.002)$ \\
\hline
\end{tabular}

Notes. The table reports estimates from a Gelbach decomposition of the employment refugee gap reported in Table 2 . The "base" specification exclusively condition on country-year fixed effects (corresponding to column 1 in Table 2). The "full" specification further conditions on dummies for gender, age, education, source area and entry cohort (corresponding to column 5 in Table 2). 
Table A 3 - Employment Refugee Gap: Additional Controls for Education

\begin{tabular}{|c|c|c|c|c|c|c|c|c|c|}
\hline & $(1)$ & $(2)$ & (3) & $(4)$ & $(5)$ & $(6)$ & $(7)$ & $(8)$ & $(9)$ \\
\hline \multirow[t]{2}{*}{ Refugee } & $-0.070 * * *$ & $-0.063 * * *$ & $-0.068 * * *$ & $-0.062 * * *$ & $-0.068 * * *$ & $-0.062 * * *$ & $-0.068 * * *$ & $-0.066 * * *$ & $-0.066 * * *$ \\
\hline & $(0.017)$ & $(0.016)$ & $(0.017)$ & $(0.017)$ & $(0.017)$ & $(0.017)$ & $(0.019)$ & $(0.019)$ & (0.019) \\
\hline \multirow[t]{2}{*}{ Highest qualification obtained in host country } & & & $0.034 * * *$ & $0.027 * * *$ & $0.041 * * *$ & $0.031 * * *$ & & $0.030 * * *$ & $0.035^{* * *}$ \\
\hline & & & $(0.010)$ & $(0.010)$ & $(0.011)$ & $(0.011)$ & & $(0.012)$ & $(0.013)$ \\
\hline \multirow[t]{2}{*}{ Highest qualification equivalent in host country } & & & & & $0.022^{*}$ & 0.013 & & & 0.010 \\
\hline & & & & & $(0.012)$ & $(0.012)$ & & & $(0.013)$ \\
\hline Host country*year & YES & YES & YES & YES & YES & YES & YES & YES & YES \\
\hline Gender, age, education & YES & YES & YES & YES & YES & YES & YES & YES & YES \\
\hline Entry Cohort*Host Country FE & & YES & & YES & & YES & YES & YES & YES \\
\hline Entry Cohort*Source Area FE & & YES & & YES & & YES & YES & YES & YES \\
\hline Field of study FE & & & & & & & YES & YES & YES \\
\hline Observations & 28,211 & 28,211 & 28,211 & 28,211 & 28,211 & 28,211 & 17,843 & 17,843 & 17,843 \\
\hline
\end{tabular}

Notes. The table reports the coefficients for a refugee migrant dummy, estimated by linear regressions with employment as the dependent variable. The sample comprises non-EU15 immigrants and refugees aged 25-64 interviewed in the 2008 survey. "Highest qualification obtained in host country" is an indicator variable for interviewees that reported to have obtained their highest qualification in the host country and "Highest qualification equivalent in host country" is an indicator variable for interviewees who managed to establish the equivalence between their qualification obtained abroad and the corresponding qualification in the host country. The excluded category includes respondents who obtained their highest qualification abroad and did not try (or manage to) establish the equivalence in the host country. All specifications include destination country-observation year interaction dummies and dummy variables for gender, five-year age groups and at most upper secondary or tertiary education (with at most lower secondary education as the excluded category) "Source Area" are dummy variables covering the seven major source regions "Entry cohort" are dummy variables for year (or grouus of years) of arrival in the host country. "Host country FE" are dummies for the twenty destination countries in the sample. In columns 7-9, we include a full set of dummies for field of study and restrict the sample to workers with tertiary education (for which the information on field is available). Robust standard errors in parentheses. $* * * p<0.01, * * p<0.05, * p<0.1$. 
Table A 4 - Economic Conditions at Entry and Scarring Effects: Other Labour Market Outcomes

\begin{tabular}{|c|c|c|c|c|c|c|c|c|c|c|}
\hline & \multicolumn{2}{|c|}{ Participation } & \multicolumn{2}{|c|}{ Unemployment } & \multicolumn{2}{|c|}{ Skilled occupation } & \multicolumn{2}{|c|}{$\begin{array}{c}\text { Bottom income } \\
\text { decile }\end{array}$} & \multicolumn{2}{|c|}{ Top income decile } \\
\hline & (1) & $(2)$ & (3) & (4) & (5) & $(6)$ & (7) & $(8)$ & (9) & (10) \\
\hline Refugee & $\begin{array}{c}-0.061^{* *} \\
(0.026)\end{array}$ & $\begin{array}{c}-0.066^{* *} \\
(0.027)\end{array}$ & $\begin{array}{c}0.031^{* * *} \\
(0.008)\end{array}$ & $\begin{array}{c}0.033^{* * *} \\
(0.008)\end{array}$ & $\begin{array}{c}-0.068^{* * *} \\
(0.018)\end{array}$ & $\begin{array}{c}-0.076^{* * *} \\
(0.021)\end{array}$ & $\begin{array}{l}0.055^{*} \\
(0.029)\end{array}$ & $\begin{array}{l}0.063^{* *} \\
(0.026)\end{array}$ & $\begin{array}{l}-0.039 \\
(0.028)\end{array}$ & $\begin{array}{c}-0.057^{* *} \\
(0.022)\end{array}$ \\
\hline Recession $_{T}$ & $\begin{array}{c}-0.035^{* *} \\
(0.014)\end{array}$ & & $\begin{array}{c}0.026 \\
(0.015)\end{array}$ & & $\begin{array}{l}-0.008 \\
(0.013)\end{array}$ & & $\begin{array}{c}0.012 \\
(0.027)\end{array}$ & & $\begin{array}{c}0.010 \\
(0.013)\end{array}$ & \\
\hline Refugee*Recession $_{\mathrm{T}}$ & & $\begin{array}{c}0.004 \\
(0.029)\end{array}$ & & $\begin{array}{c}0.006 \\
(0.021)\end{array}$ & & $\begin{array}{l}-0.005 \\
(0.027)\end{array}$ & & $\begin{array}{l}-0.023 \\
(0.045)\end{array}$ & & $\begin{array}{c}0.130 \\
(0.092)\end{array}$ \\
\hline Baseline controls and FE & YES & YES & YES & YES & YES & YES & YES & YES & YES & YES \\
\hline Entry Cohort*Host Country FE & & YES & & YES & & YES & & YES & & YES \\
\hline Observations & 60,477 & 60,477 & 47,274 & 47,274 & 41,204 & 41,204 & 12,207 & 12,207 & 12,207 & 12,207 \\
\hline
\end{tabular}

Notes. The table reports estimated coefficients from linear regressions of dummies for participation (columns 1-2), unemployment (columns 3-4), having a skilled occupation (if employed; column 7-8) and being in the bottom and top decile of the income distribution (columns 7-8 and 9-10, respectively) on a refugee migrant dummy, a recession indicator (at the time of migration, $\mathrm{T}$ ) and their interaction. "Baseline controls and FE" include: destination country-observation year interaction dummies; dummy variables for gender, five-year age groups, education levels and source areas. "Entry cohort" are dummy variables for year (or groups of years) of arrival in the host country. "Host Country" are dummy variables for destination countries. Standard errors (in parentheses) are clustered at the host country level: $* * * \mathrm{p}<0.01, * * \mathrm{p}<0.05, * \mathrm{p}<0.1$ 
Table A 5 - Dispersal Policies in Europe

\begin{tabular}{|c|c|c|c|c|}
\hline Country & $\begin{array}{l}\text { EULFS } \\
\text { Sample }\end{array}$ & Active DP & Description & Sources \\
\hline Denmark & NO & $\begin{array}{l}\text { First phase (1986- } \\
1998) ; \text { Second } \\
\text { phase (since 1999) }\end{array}$ & $\begin{array}{l}\text { Denmark introduced a dispersal policy for recognized refugees in } 1986 \text {, aiming at } \\
\text { an even distribution across municipalities and at avoiding concentration in areas } \\
\text { which aready had high shares of immigrants. With the enactment of the } \\
\text { "Integration Law" in } 1999 \text { the allocation system was reformed. The "introduction } \\
\text { programme" for refugees was extended from } 18 \text { monthth to } 3 \text { years and more } \\
\text { constraints to the possibility of moving out of the assigned municipality were } \\
\text { introduced. }\end{array}$ & $\begin{array}{l}\text { Nielsen, C.P. and K.B. Jensen (2006), “The Danish Integration Act's Significance for the Settlement } \\
\text { Patterns of } \\
\text { Refugees", Copenhagen: Institute for Local Government Studies.; Damm, Anna Piil, 2009. Ethnic } \\
\text { enclaves and immigrant labor makret outcomes: quasi-experimental evidence. J Labor Econ., 27(2), } \\
\text { 281-314;; Azlor, L., Damm, A.P. and Schultz-Nielsen, M.L., 2020. Local labour demand and immigrant } \\
\text { employment. Labour Economics, In Press. }\end{array}$ \\
\hline Finland & Yes & Since 1988 & $\begin{array}{l}\text { The Finnish policy since } 1988 \text { has been to disperse refugees throughout the } \\
\text { country. The state provides accommodation for asylum seeekers at refugee } \\
\text { reception centres (located in different areas of the country) until their } \\
\text { aplication is processede. These who are granted a residence permit are then } \\
\text { allocated to a specific municipality and entitled to integration measures. }\end{array}$ & $\begin{array}{l}\text { Andersson, R., Dhalmann, H., Holmquist, E., Kauppinen, T. M., Turner, L. M., Skifter Andersen, H. and ... } \\
\text { Yousfi, S. 2010. Immigration, housing and segregation in the Nordic welfare states, Helsinki: } \\
\text { Department of Geosciences and Geography, University of Helsinki. }\end{array}$ \\
\hline Germany & Yes & Since 1991 & $\begin{array}{c}\text { In Germany asylum seekers are allocated to Lander according to the königstein } \\
\text { rule - a predetermined rule that combines total tax revenues and population } \\
\text { numbers - and which is re-calculated annually. Asylum seekers are then allocated } \\
\text { to districts within Lander, in which are required to stay, using state-specific } \\
\text { allocation key as guidance. }\end{array}$ & 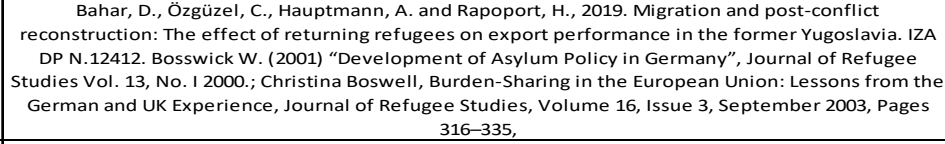 \\
\hline Ireland & Yes & Since 2000 & $\begin{array}{l}\text { In } 2000 \text { the Government announced a policy of dispersal of protection applicants } \\
\text { throughout the country with the aim of avoiding a disproportionate burden on } \\
\text { State services accessible to protection applicants. The dispersal location is made } \\
\text { largely on the basis of family composition and available housing. }\end{array}$ & $\begin{array}{l}\text { Paola Proietti, Paolo Veneri, (2019) The Location of Hosted Asylum Seekers in OECD Regions and Cities, } \\
\text { Journal of Refugee Studies, forthcoming }\end{array}$ \\
\hline Netherlands & Yes & Since 1987 & $\begin{array}{l}\text { The 'Regulation Reception of Asylum Seekers' (Regeling Opvang Asielzoekers, } \\
\text { ROA) that became effective in } 1987 \text { established that asylum seekers, like the } \\
\text { quota refugees, would initially be housed in centrally operated reception } \\
\text { centres, and after that in specialized housing. }\end{array}$ & $\begin{array}{l}\text { Joan Van Selm “Asylum in the Netherlands: A Hazy Shade of Purple” Journal of Refugee Studies Vol. 13, } \\
\text { No. } 12000 \text {, Pages 74-90; Andersson (2003) Settlement Dispersal of Immigrants and Refugees in Europe: } \\
\text { Policy and Outcomes, WP }\end{array}$ \\
\hline Norway & Yes & Since 1994 & $\begin{array}{l}\text { Since 1994, the Norwegian government has pursued the objective of settling } \\
\text { refugees throughout the entire country. The proportion of refugees settled in } \\
\text { each county roughly corresponds to the county proportion of the overall } \\
\text { population. }\end{array}$ & $\begin{array}{l}\text { Djuve_Kavli__Norway_2000- “Living conditions and relocations among refugees in Norway, in light of } \\
\text { the government's resettlement work", fafo report 344; Valenta and Bunar (2010) "State Assisted } \\
\text { Integration: Refugee Integration Policies in ScandinavianWelfare States: the Swedish and Norwegian } \\
\text { Experience" Journal of Refugee Studies Vol. 23, No. } 4\end{array}$ \\
\hline Sweden & Yes & From 1985 to 1994 & \begin{tabular}{|c|} 
The DP was introduced in 1985 (the so-called "Whole of Sweden Strategy") and \\
enforced until 1994. Since 1994, asylum seekers have been able to look for their \\
own housing and are entitled to housing allowances, or alternatively a free place \\
in an asylum location.
\end{tabular} & $\begin{array}{l}\text { Habereld et al. "Selectivity and Internal Migration: A Study of Refugees' Dispersal Policy in Sweden", } \\
\text { Front. Sociol., 13 September 2019; Bevelander, P. (2010). "The immigration and integration experience: } \\
\text { the case of Sweden," in Immigration Worldwide Policices, Practices, and Trends, eds U. A. Segal, D. } \\
\text { Elliott, and N. S. Mayadas (New York, NY: Oxford Univ Press); Edic, P., Fredriksson, P., and Âslund, O. } \\
\text { (2004). Settlement policies and the economic success of immigrants. J. Populat. Econ. 17, 133-155. }\end{array}$ \\
\hline Switzerland & Yes & Since 1988 & $\begin{array}{c}\text { A dispersal policy was introduced with an amendment to the Aliens Law in 1988, } \\
\text { to minimize self-segregation and ghetto effects } \\
\text { and avoid social tension between natives and asylum seekers. During their } \\
\text { waiting period, asylum seekers are housed in accommodations in a randomly } \\
\text { assigned Swiss canton and they are not allowed to leave this canton. Mobility } \\
\text { restrictions persist also after the conclusion of the application screening process. }\end{array}$ & 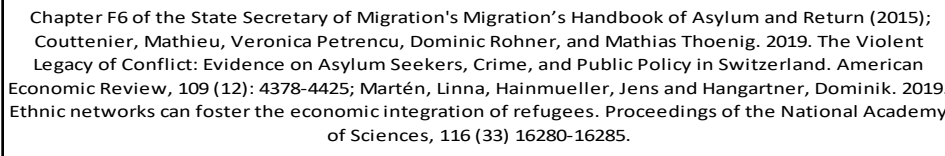 \\
\hline UK & Yes & Since 2000 & $\begin{array}{l}\text { The } 1999 \text { Immigration and Asylum Act (IAA) introduced a dispersal policy } \\
\text { for asylum seekers which was implemented from } 2000 \text { onwards. When they apply } \\
\text { for accommodation, asylum seekers are allocateded to temporary accommodation } \\
\text { centers across the UK and live there for the first few weeks. They are then } \\
\text { assigned to a } \\
\text { specific Local Authority that places them in one of its available housing units } \\
\text { where they can stay until their refugee status is determined. The UK dispersal } \\
\text { policy explicitly denies asylum seekers the right to have a say in the choice of } \\
\text { their destination and aims at placing them away from Greater London or the } \\
\text { South East of England. Asslum seekers whose refugee status is recognized are } \\
\text { entitled to request social housing but they must apply in the same Local } \\
\text { Authorities they were dispersed to and live there for at least } 6 \text { months. }\end{array}$ & $\begin{array}{l}\text { Bell, Brian, Fasani, Francesco, Machin, Stephen, 2013. Crime and immigration: evidence from large } \\
\text { immigrant waves. Review of Economics and Statistics, 21(3), 1278-1290. }\end{array}$ \\
\hline
\end{tabular}


Table A 6 - Robustness of Dispersal Policy Effect to Country-Specific Shocks at Arrival

\begin{tabular}{|c|c|c|c|c|c|c|c|c|c|c|}
\hline & (1) & (2) & (3) & (4) & (5) & (6) & (7) & (8) & (9) & (10) \\
\hline & \multicolumn{10}{|c|}{ Panel A: Employment } \\
\hline \multirow[t]{3}{*}{ Refugee * Dispersal Policy } & $-0.054 * *$ & $-0.056 * * *$ & $-0.056 * *$ & $-0.061 * * *$ & $-0.067 * * *$ & -0.040 & -0.038 & -0.044 & -0.049 & -0.048 \\
\hline & $(0.020)$ & (0.019) & $(0.022)$ & $(0.020)$ & $(0.023)$ & $(0.029)$ & $(0.024)$ & $(0.039)$ & $(0.031)$ & $(0.035)$ \\
\hline & \multicolumn{10}{|c|}{ Panel B: Participation } \\
\hline \multirow{2}{*}{ Refugee $*$ Dispersal Policy } & $-0.046^{*}$ & $-0.051 * *$ & $-0.041 * *$ & $-0.051^{*}$ & $-0.052 * *$ & $-0.056 * * *$ & $-0.058 * * *$ & $-0.045^{* *}$ & $-0.061 * * *$ & $-0.049 * *$ \\
\hline & $(0.023)$ & $(0.022)$ & $(0.016)$ & $(0.024)$ & $(0.019)$ & $(0.019)$ & $(0.018)$ & $(0.021)$ & $(0.018)$ & $(0.021)$ \\
\hline Refugee * Economic conditions (_T) & & YES & & & YES & & YES & & & YES \\
\hline Refugee ${ }^{*}$ Asylum appl. \& refugee pop. ( & & & YES & & YES & & & YES & & YES \\
\hline Refugee * Government ideology (_T) & & & & YES & YES & & & & YES & YES \\
\hline Baseline controls and FE & YES & YES & YES & YES & YES & YES & YES & YES & YES & YES \\
\hline Entry Cohort * Host Country FE & YES & YES & YES & YES & YES & YES & YES & YES & YES & YES \\
\hline Refugee $*$ Entry Cohort FE & YES & YES & YES & YES & YES & YES & YES & YES & YES & YES \\
\hline Refugee $*$ Host Country FE & & & & & & YES & YES & YES & YES & YES \\
\hline Observations & 55,508 & 55,508 & 55,508 & 55,508 & 55,508 & 55,508 & 55,508 & 55,508 & 55,508 & 55,508 \\
\hline
\end{tabular}

Notes. The table reports estimated coefficients from linear regressions of employment (Panel A) and participation (Panel B) on the interaction term between a refugee dummy and a Dispersal Policy indicator (which is equal to one if a DP was in place in the country of destination in the year of arrival, T). In columns 2 and 7 , we control for economic conditions at the time of arrival (T), measured with a recession indicator. In column 3 and 8, we control for control for asylum applications and stock of refugees (both in logs) at time T, taken from Eurostat. In columns 4 and 9 we control for government ideology at time T, measured with a left-right scale (going from 0 to 10) elaborated from data provided by ParlGov (http://www.parlgov.org//). In column 4 we control for asylum applications and stock of refugees (both in logs) at time T, taken from Eurostat. In columns 5 and 10, we simultaneously control for all the previous variables. The sample comprises non-EU15 immigrants aged $25-64$ who have arrived in Europe from year 1980 onward. "Baseline controls and FE" include: destination country-observation year interaction dummies; dummy variables for gender, five-year age groups, education levels and source areas. Standard errors (in parentheses) are clustered at the host country level: ${ }^{* * *} \mathrm{p}<0.01,{ }^{* *} \mathrm{p}<0.05,{ }^{*} \mathrm{p}<0.1$. 
Table A 7 - Recessions and Dispersal Policies at Arrival and Employment Probability - Alternative Clustering and Wild Bootstrap

\begin{tabular}{|c|c|c|c|c|c|c|c|c|c|c|c|c|}
\hline & \multirow[t]{2}{*}{ (1) } & \multirow[t]{2}{*}{ (2) } & (3) & (4) & (5) & (6) & \multirow[t]{2}{*}{ (7) } & \multirow[t]{2}{*}{ (8) } & \multirow{2}{*}{\multicolumn{3}{|c|}{$\begin{array}{lr}(10) & (11) \\
\text { Dispersal Policy }\end{array}$}} & \multirow[t]{2}{*}{ (12) } \\
\hline & & & \multicolumn{4}{|c|}{ Recession } & & & & & & \\
\hline & All $\mathrm{Mi}$ & grants & YSM & $1<=10$ & Econom & ic Migr. & \multicolumn{2}{|c|}{ Non-Econ. Migr. } & \multicolumn{3}{|c|}{ Full sample } & YSM $<=10$ \\
\hline Refugee & $\begin{array}{c}-0.078^{* * *} \\
(0.027)\end{array}$ & $\begin{array}{c}-0.082^{* * *} \\
(0.027)\end{array}$ & $\begin{array}{c}-0.175^{* * *} \\
(0.040)\end{array}$ & $\begin{array}{c}-0.184 * * * \\
(0.039)\end{array}$ & $\begin{array}{c}-0.183^{* * *} \\
(0.041)\end{array}$ & $\begin{array}{c}-0.171^{* * *} \\
(0.042)\end{array}$ & $\begin{array}{l}-0.050^{*} \\
(0.024)\end{array}$ & $\begin{array}{c}-0.056^{* *} \\
(0.024)\end{array}$ & $\begin{array}{c}-0.059 * * * \\
(0.014)\end{array}$ & & & \\
\hline Recession $_{\mathrm{T}}$ & $\begin{array}{c}-0.046^{* *} \\
(0.020)\end{array}$ & & $\begin{array}{c}-0.043^{* *} \\
(0.019)\end{array}$ & & $\begin{array}{c}0.014 \\
(0.013)\end{array}$ & & $\begin{array}{c}-0.084^{* * *} \\
(0.029)\end{array}$ & & & & & \\
\hline Refugee*Recession $_{\mathrm{T}}$ & & $\begin{array}{l}-0.004 \\
(0.029)\end{array}$ & & $\begin{array}{c}0.056 \\
(0.050)\end{array}$ & & $\begin{array}{c}-0.084^{* *} \\
(0.036)\end{array}$ & & $\begin{array}{c}0.030 \\
(0.030)\end{array}$ & & & & \\
\hline Refugee*Dispersal Policy $_{T}$ & & & & & & & & & $\begin{array}{l}-0.053 \\
(0.031)\end{array}$ & $\begin{array}{c}-0.047^{* *} \\
(0.018)\end{array}$ & $\begin{array}{l}-0.045^{*} \\
(0.025)\end{array}$ & $\begin{array}{c}-0.175^{* * *} \\
(0.056)\end{array}$ \\
\hline $\begin{array}{l}\text { Coeff. condition at entry (T) - p-values: } \\
\text { cluster(country-entry cohort) }\end{array}$ & 0.00 & 0.89 & 0.01 & 0.31 & 0.27 & 0.06 & 0.00 & 0.30 & 0.14 & 0.03 & 0.10 & 0.01 \\
\hline cluster(country) & 0.04 & 0.88 & 0.04 & 0.29 & 0.31 & 0.03 & 0.01 & 0.33 & 0.10 & 0.02 & 0.09 & 0.01 \\
\hline wild cluster bootstrap - cluster (country) & 0.06 & 0.89 & 0.06 & 0.36 & 0.43 & 0.05 & 0.02 & 0.41 & 0.16 & 0.01 & 0.18 & 0.01 \\
\hline Observations & 60,477 & 60,477 & 30,199 & 30,199 & 30,829 & 30,829 & 34,630 & 34,630 & 60,480 & 60,480 & 60,480 & 30,202 \\
\hline Baseline controls and FE & YES & YES & YES & YES & YES & YES & YES & YES & YES & YES & YES & YES \\
\hline Entry Cohort*Host Country FE & & & YES & & & YES & & YES & YES & YES & YES & YES \\
\hline Refugee*Entry Cohort FE & & & & & & & & & & YES & YES & YES \\
\hline Refugee*Host Country FE & & & & & & & & & & & YES & YES \\
\hline
\end{tabular}

Notes. The table reports estimates of the effects on current employment probability of being exposed to a recession (columns 1-8) or to a dispersal policy (columns 9-12) at the time of arrival T in the host country. Estimates in columns 1-8 replicate those reported in Table 6 (columns 2-3 and 5-6 in Panel A and B) while those in columns 9-12 replicate those reported in Table 8 (columns 1-3, Panel A) and Table 9 (column 1, Panel A). All controls and fixed effects are defined as in those tables. Standard errors (in parentheses) are clustered at the host country level: $* * * \mathrm{p}<0.01, * * \mathrm{p}<0.05, * \mathrm{p}<0.1$. Below the estimates, we report the p-values for the estimated coefficients on the conditions at entry (i.e. recession at time $\mathrm{T}$ in columns 1, 3, 5 and 7 ; recession at time $\mathrm{T}$ interacted with refugee dummy in columns 2, 4, 6 and 8); dispersal policy at time T interacted with refugee dummy (in columns 9-12) which were obtained by: i) clustering at the entry cohort-host country level; ii) clustering at the host country level; iii) clustering at the host country level and using wild cluster bootstrap. The wild cluster bootstrapped p-values are estimated using the STATA package boottest developed by Roodman et al. (2019) (with normal weights and 9999 replications). 